\title{
əRadiative Effect of Clouds at Ny-Ålesund, Svalbard, as Inferred from Ground-Based Remote Sensing Observations
}

\author{
KERSTIN EBELL AND TATIANA NOMOKONOVA \\ Institute for Geophysics and Meteorology, University of Cologne, Cologne, Germany \\ MARION MATURILLI AND CHRISTOPH RITTER \\ Alfred Wegener Institute, Helmholtz Centre for Polar and Marine Research, Potsdam, Germany
}

(Manuscript received 2 April 2019, in final form 16 October 2019)

\begin{abstract}
For the first time, the cloud radiative effect (CRE) has been characterized for the Arctic site Ny-Ålesund, Svalbard, Norway, including more than 2 years of data (June 2016-September 2018). The cloud radiative effect, that is, the difference between the all-sky and equivalent clear-sky net radiative fluxes, has been derived based on a combination of ground-based remote sensing observations of cloud properties and the application of broadband radiative transfer simulations. The simulated fluxes have been evaluated in terms of a radiative closure study. Good agreement with observed surface net shortwave (SW) and longwave (LW) fluxes has been found, with small biases for clear-sky (SW: $3.8 \mathrm{~W} \mathrm{~m}^{-2} ; \mathrm{LW}:-4.9 \mathrm{~W} \mathrm{~m}^{-2}$ ) and all-sky (SW: $-5.4 \mathrm{~W} \mathrm{~m}^{-2}$; LW: $-0.2 \mathrm{~W} \mathrm{~m}^{-2}$ ) situations. For monthly averages, uncertainties in the CRE are estimated to be small $\left(\sim 2 \mathrm{~W} \mathrm{~m}^{-2}\right)$. At Ny-Ålesund, the monthly net surface CRE is positive from September to April/May and negative in summer. The annual surface warming effect by clouds is $11.1 \mathrm{~W} \mathrm{~m}^{-2}$. The longwave surface CRE of liquid-containing cloud is mainly driven by liquid water path (LWP) with an asymptote value of $75 \mathrm{~W} \mathrm{~m}^{-2}$ for large LWP values. The shortwave surface CRE can largely be explained by LWP, solar zenith angle, and surface albedo. Liquid-containing clouds (LWP $>5 \mathrm{~g} \mathrm{~m}^{-2}$ ) clearly contribute most to the shortwave surface CRE $(70 \%-98 \%)$ and, from late spring to autumn, also to the longwave surface CRE (up to $95 \%$ ). Only in winter are ice clouds (IWP $>0 \mathrm{~g} \mathrm{~m}^{-2}$; LWP $<5 \mathrm{~g} \mathrm{~m}^{-2}$ ) equally important or even dominating the signal in the longwave surface CRE.
\end{abstract}

\section{Introduction}

In the last decade, the Arctic has experienced significant changes (Stroeve et al. 2012; Jeffries et al. 2013) and exhibited an increase in near-surface air temperature that is more than twice as large as the observed increase in global mean temperature (Serreze and Barry 2011; Wendisch et al. 2017). This so-called Arctic amplification is due to many feedback processes, the mechanisms and relative contributions of which are still under debate and the focus of current research (e.g., Wendisch et al. 2017; Screen et al. 2018; Goosse et al. 2018). On a local scale, clouds strongly influence Arctic climate feedbacks (Kay et al. 2016). Their interaction with

D Denotes content that is immediately available upon publication as open access.

Corresponding author: Kerstin Ebell, kebell@meteo.uni-koeln.de longwave and shortwave radiation can be quite complex due to the special boundary and atmospheric characteristics in the Arctic, for example, a high surface albedo, large solar zenith angles, low temperatures, frequently occurring temperature inversions, and a dry atmosphere (Curry et al. 1996). The impact of clouds on atmospheric radiative fluxes and heating rates strongly depends on the cloud macrophysical (e.g., frequency of occurrence and cloud vertical distribution) and microphysical (e.g., phase, water content, and hydrometeor size distribution) properties. To better understand the processes of cloudradiation interactions in the Arctic, cloud, thermodynamic, and boundary conditions need to be well known.

Satellite observations can provide a broad picture of clouds and radiative fluxes and also describe their spatial variability within the whole Arctic region (Cesana et al. 2012; Kay and L'Ecuyer 2013; Sedlar and Tjernström 2017). Kay and L'Ecuyer (2013), for example, analyzed cloud observations from active and passive satellite 
instrumentation together with observed and calculated radiative fluxes. They found that, on average, clouds over the Arctic ocean warm the surface by $10 \mathrm{~W} \mathrm{~m}^{-2}$ and cool the top of the atmosphere by $-12 \mathrm{~W} \mathrm{~m}^{-2}$. For a more detailed view on clouds, ground-based remote sensing observations taken during field campaigns or performed continuously at fixed sites provide complementary information. Shupe et al. (2004), for example, analyzed a year of data from the Surface Heat Budget of the Arctic Ocean (SHEBA) ship campaign, which took place in the Beaufort and Chukchi Seas from October 1997 to October 1998. They used a combination of active and passive ground-based remote sensing observationsfor example, cloud radar, lidar, and microwave radiometer and surface radiation measurements-to characterize clouds and their radiative impact on the surface. Shupe et al. (2004) found an annual mean longwave warming by liquid- or ice-containing clouds of 52 or $16 \mathrm{~W} \mathrm{~m}^{-2}$, respectively, and a shortwave cooling effect by -21 or $-3 \mathrm{~W} \mathrm{~m}^{-2}$, respectively. Sedlar et al. (2011) presented results from the Arctic Summer Cloud Ocean Study (ASCOS), which took place near $87.5^{\circ} \mathrm{N}$ from August to early September 2008, and found a net warming effect of clouds for this time and location. Recently, comprehensive cloud and radiation observations were performed during the ship- and airborne-based Physical Feedbacks of Arctic Boundary Layer, Sea Ice, Cloud and Aerosol (PASCAL) and Arctic Cloud Observations Using Airborne Measurements during Polar Day (ACLOUD) campaigns (Wendisch et al. 2019), which took place in May/June 2017 in the vicinity of Svalbard, Norway.

Although such campaigns provide a wealth of information from various instrumentation for the inner Arctic, they are always limited to a certain time period. In addition to ground-based campaign observations, long-term single-point time series from ground-based "supersites" are needed so that 1 ) clouds and their radiative impact can be characterized temporally and vertically highly resolved and 2) robust statistics can be provided since clouds are observed under all atmospheric conditions in all seasons. One of the longest time series in this respect are the observations performed within the Atmospheric Radiation Measurement Program in Barrow, Alaska (now known as Utqiagivik; Verlinde et al. 2016). Further supersites are located in Eureka, Canada (de Boer et al. 2009), and Summit, Greenland (Shupe et al. 2013). Dong et al. (2010) analyzed 10 years of cloud observations and the radiative impact of clouds on the surface at Barrow. By comparing observed surface radiative fluxes with clear-sky flux estimates from an empirical curve-fitting technique (Long and Ackerman 2000; Long and Turner 2008), they found an annual averaged net surface cloud radiative effect of $3.5 \mathrm{~W} \mathrm{~m}^{-2}$. Cox et al. (2016) extended the analysis using $22 \mathrm{yr}$ of cloud radiative forcing data at Barrow and also set the cloud radiative forcing in spring in context to autumn sea ice extent. They found a significant negative correlation between net cloud radiative forcing in April-May and sea ice extent in September. From infrared spectrometer measurements and clear-sky radiative transfer simulations, Cox et al. (2012) compared the downward longwave cloud radiative forcing at Eureka with the one at Barrow. They found that the yearly mean longwave cloud radiative forcing at Eureka $\left(27 \mathrm{~W} \mathrm{~m}^{-2}\right)$ is only one-half of that at Barrow $\left(48 \mathrm{~W} \mathrm{~m}^{-2}\right)$. The lower longwave surface cloud forcing at Eureka is partly due to the lower cloud fraction and the higher altitudes of clouds at this site (Cox et al. 2012). Miller et al. (2015) performed a study on the radiative effects of clouds at Summit using almost 3 years of cloud and radiation observations. Clear-sky fluxes were calculated with a broadband radiative transfer model and then compared to observed all-sky fluxes. In this way, Miller et al. (2015) found a pronounced net cloud warming of $33 \mathrm{~W} \mathrm{~m}^{-2}$ of the central Greenland surface that is due to the high surface albedo all year round.

The atmospheric observatory of the Arctic FrenchGerman research station named from the Alfred Wegener Institute for Polar and Marine Research and French Polar Institute Paul Emile Victor (AWIPEV) at Ny-Ålesund, Svalbard, Norway, has recently also been equipped with a cloud radar (Nomokonova et al. 2019). Ny-Ålesund $\left(78.925^{\circ} \mathrm{N}, 11.930^{\circ} \mathrm{E}\right)$ is situated at the southern coast of the Kongsfjord. The area around $\mathrm{Ny}$-Ålesund represents a typical tundra system surrounded by glaciers, mountains, moraines, and rivers. A detailed map of the complex topography can be found in Maturilli et al. (2013). Ny-Ålesund is located in the warmest part of the Arctic and exhibits strong signals of climate change (Maturilli et al. 2015).

AWIPEV operates a comprehensive and state-ofthe-art instrument suite, in particular, for thermodynamic, aerosol, trace gas, and surface radiation observations where some of the observations started more than 30 years ago. Cloud observations based on ceilometer measurements (i.e., basically cloud base height) are available for more than 20 years (Maturilli and Ebell 2018). Combining the highly vertically and temporally resolved cloud radar observations with the collocated remote sensing instrumentation at AWIPEV allows for a much more comprehensive characterization of the cloud macro- and microphysical properties than before. Currently, more than 2 years of cloud radar data, that is, from 10 June 2016 to 5 October 2018, are available, and further multiyear, continuous cloud radar observations are planned. Thus, the Ny-Ålesund observations add 
valuable information to the existing Arctic ground-based cloud climatologies.

In this paper, we focus on the analysis of the impact of clouds on the surface radiative fluxes at $\mathrm{Ny}$-Ålesund. Since only a few days with cloud radar observations are available for October 2018, we have only analyzed the time period June 2016 to September 2018 in this study. More details on the instrumentation and on some of the cloud retrieval algorithms are provided in the paper by Nomokonova et al. (2019), who also showed some first statistics of cloud properties at Ny-Ålesund based on the first year of cloud radar observations. In this study, we extend the analysis to the whole time period of the cloud radar operation and put the focus on the cloud radiative effect (CRE) - in other studies also called cloud radiative forcing (Dong et al. 2010; Miller et al. 2015)—which is defined as the difference between the all-sky net radiative flux and the net flux of the equivalent clear-sky scene.

In the next section, we briefly describe the instrumentation, cloud retrieval algorithms, and setup of the broadband radiative transfer simulations that are used to assess the CRE. Before analyzing the results in more detail, we first provide an evaluation of our simulated surface fluxes to gain confidence in the radiative transfer simulations. The cloud radiative effect at $\mathrm{Ny}$-Alesund is then analyzed for the surface, the top of atmosphere, and the atmosphere. The latter is calculated as the difference between the values at the top of the atmosphere and the surface. Particular focus is put on the surface $\mathrm{CRE}$ and its dependency on surface albedo, solar zenith angle, and the amount of liquid and ice water. Also, the individual contributions of liquid- and ice-containing clouds to surface CRE are assessed.

\section{Method}

In this section, we will give a short summary of the various instruments used, the cloud macro- and microphysical retrieval algorithms applied, and the setup of the broadband radiative transfer calculations.

\section{a. Instruments}

To observe vertically resolved cloud properties from ground-based instrumentation, a combination of different instruments is beneficial. Here, we exploit information from a cloud radar, a microwave radiometer (MWR), and a ceilometer. Details on these instruments and data processing are already given in Nomokonova et al. (2019). We will thus give a brief summary and add information on the additional datasets used.

The cloud radar operated at Ny-Ålesund is a frequencymodulated continuous-wave $94-\mathrm{GHz}$ Doppler radar from the University of Cologne (Küchler et al. 2017).
The data of two different instruments, the Jülich $\mathrm{Ob}$ servatory for Cloud Evolution (JOYCE) Radar-94 GHz (JOYRAD-94) and Microwave Radar/Radiometer for Arctic Clouds-A (MiRAC-A), are used in the study. Both instruments are similar in design except that the antenna of MiRAC-A is smaller than of JOYRAD-94 to accommodate MiRAC-A being deployed on an aircraft. JOYRAD-94 was operated from 16 June 2016 to 27 July 2017, and MiRAC was measuring from 28 July 2017 to 8 October 2018. Profiles of cloud radar reflectivity factor $Z$ and Doppler velocity are used for the retrieval of cloud macro- and microphysical properties.

While cloud radars are sensitive to the vertical profile of hydrometeors, these radars are less sensitive to small liquid droplets. Thus, ceilometers, which are much more sensitive to these small drops, provide very complementary observations of the cloud-base height and the location of these drops (until the laser is extinguished). Here we use attenuated backscatter profiles from the Vaisala ceilometer CL51 of the Alfred Wegener Institute (AWI), which has been operating at the AWIPEV atmospheric observatory since 2011 (Maturilli and Ebell 2018).

Information on liquid water path (LWP) and integrated water vapor (IWV) is retrieved from the multifrequency microwave radiometer Humidity and Temperature Profiler (HATPRO) of AWI. Detailed information about the processing of the MWR data is given by Nomokonova et al. (2019). The MWR retrievals for LWP and IWV are based on multivariate linear regression algorithms. Typical uncertainties for LWP are around $20-25 \mathrm{~g} \mathrm{~m}^{-2}$. For IWV, uncertainties are smaller than $1 \mathrm{~kg} \mathrm{~m}^{-2}$. A comparison with $\mathrm{Ny}$-Ålesund radiosondes revealed IWV differences of $0.85 \mathrm{~kg} \mathrm{~m}^{-2}$. The LWP is used to correct the cloud radar reflectivity for liquid attenuation effects and to estimate the liquid water content and effective radius profiles as described in the next section. When available, IWV data are used to scale the humidity profile used in the broadband radiative transfer calculations.

The instrumentation of the Baseline Surface Radiation Network (BSRN) provides not only surface radiation observations with high accuracy and temporal resolution of $1 \mathrm{~min}$ but also basic surface meteorological data (Maturilli et al. 2015, 2013). The surface radiation observations encompass direct solar radiation by a pyrheliometer mounted on a solar tracker (Eppley NIP); diffuse, global, and reflected shortwave radiation by pyranometers (Kipp and Zonen CMP22); and up- and downward longwave radiation by pyrgeometers (Eppley PIR). All data are quality controlled. Pyrgeometer measurements of longwave downward radiation are expected to have an uncertainty not greater than $\pm 10 \mathrm{~W} \mathrm{~m}^{-2}$, and measurements of global radiation are expected to have a maximum uncertainty of $\pm 20 \mathrm{~W} \mathrm{~m}^{-2}$ (Lanconelli et al. 2011). 
TABLE 1. Overview of applied cloud microphysical retrieval algorithms.

\begin{tabular}{lc}
\hline \multicolumn{1}{c}{ Cloud property } & \multicolumn{1}{c}{ Retrieval method } \\
\hline Liquid water content & $\begin{array}{c}\text { Liquid only clouds: Frisch et al. (1998) using radar reflectivity factor } Z \text { and liquid water path (LWP) from } \\
\text { microwave radiometer; mixed/multilayer clouds: scaled adiabatic LWC profile using LWP from MWR } \\
\text { Liquid only clouds: Frisch et al. (2002) using } Z \text { and MWR LWP; mixed/multilayer clouds: climatological } \\
\text { Liquid effective radius }\end{array}$ \\
$\begin{array}{l}\text { Hogan of } 5 \mu \mathrm{m} \\
\text { Ice water content }\end{array}$ & $\begin{array}{l}\text { Delanoë and Hogan (2010) using IWC and visible extinction coefficient } \alpha \text { from Hogan et al. (2006); IWC } \\
\text { Ice effective radius }\end{array}$ \\
& and $\alpha$ are both functions of $Z$ and $T$ \\
\hline
\end{tabular}

The BSRN 10-m air temperature is directly used as input to the radiative transfer calculations. The shortwave flux components were used to estimate the direct and diffuse surface albedo (see section on the radiative transfer calculations). Measurements of surface solar and terrestrial radiation are used to evaluate the radiative transfer results.

\section{b. Retrieval of cloud macro- and microphysical properties}

As already presented by Nomokonova et al. (2019), the Cloudnet retrieval algorithm suite (Illingworth et al. 2007) is applied to the measurements at the AWIPEV atmospheric observatory. First, the Cloudnet target categorization product is generated, which provides vertically resolved information on the presence of cloud liquid droplets, ice, melting ice, and drizzle/rain in each radar height bin. To this end, profiles of cloud radar reflectivity, Doppler velocity, and ceilometer attenuated backscatter are jointly analyzed with numerical weather prediction data. The resulting categorization profiles have temporal and vertical resolutions of $30 \mathrm{~s}$ and $20 \mathrm{~m}$, respectively, and provide information up to a height of about $12 \mathrm{~km}$. On the basis of this target classification, we subsequently apply corresponding retrieval algorithms for liquid water content (LWC), for ice water content (IWC), and for the effective radii $r_{e, \text { liq }}$ and $r_{e, \text { ice }}$ of cloud liquid and ice, respectively.

Depending on the cloud situation, different microphysical retrieval algorithms are applied. These are summarized in Table 1 . If ice particles occur, ice water content is calculated from radar reflectivity $Z$ and temperature $T$ (Hogan et al. 2006), which is also a standard algorithm of Cloudnet. Theoretical uncertainties of the IWC retrieval were estimated to range between $-33 \%$ and $+50 \%$ for temperatures above $-20^{\circ} \mathrm{C}$ (Hogan et al. 2006). The effective radius of ice particles is calculated following Delanoë and Hogan (2010) where IWC and the visible extinction coefficient are input variables. The latter one is also calculated as a function of $Z$ and $T$ (Hogan et al. 2006). Relative uncertainties for the effective radius of ice are reported to be about $30 \%$ (Delanoë and Hogan 2010). If both ice and liquid are present in a radar bin, it is assumed that ice dominates the signal in $Z$ (Shupe et al. 2004) and the same retrieval algorithms for pure ice clouds are applied.

LWC and $r_{e, \text { liq }}$ are retrieved for all radar bins in which cloud droplets occur. For single-layer water clouds, LWC can be calculated using the relation by Frisch et al. (1998). Here, the LWP of the MWR is distributed vertically following the shape of the radar reflectivity profile. This method also works for cases when ice clouds are located above the single-layer liquid cloud. The liquid effective radius $r_{e, \text { liq }}$ in these cases is derived from Frisch et al. (2002), which also uses LWP and $Z$ as input. Note that Frisch et al. (2002) assume a lognormal droplet size distribution with a fixed spectral width that is here set to 0.3 . They found an uncertainty of about $20 \%$ for the liquid effective radius.

In the case of mixed-phase clouds, in particular, when both liquid and ice occur in the same radar bin, we do not know the radar reflectivity associated with cloud liquid droplets only, and the Frisch et al. (1998) technique is not applicable. Thus, an adiabatic LWC profile is calculated in these cases and scaled in such a way that the integrated liquid water content is equal to the observed LWP from the MWR. A similar approach was taken by Shupe et al. (2015). This scaled adiabatic method is also applied for multilayer liquid clouds. The effective radius in these cases is assumed to be $5 \mu \mathrm{m}$, which represents the median value of liquid effective radius of all observed cases at Ny-Ålesund where the algorithm by Frisch et al. (2002) is applicable. Note that no microphysical properties are retrieved for rain or drizzle particles. Also, if rain or drizzle occurs in a liquid cloud, the methods by Frisch et al. (1998) and Frisch et al. (2002) cannot be applied. In these cases, $Z$ is dominated by the few large rain droplets and is not proportional to the LWC anymore. Thus, a scaled adiabatic LWC profile and the climatological value for $r_{e, \text { liq }}$ are assumed. This dataset of retrieved cloud microphysical properties has been recently published by Nomokonova and Ebell (2019).

\section{c. Broadband radiative transfer calculations}

To characterize the radiative effects of clouds at Ny-Ålesund, the retrieved cloud microphysical properties serve as an input to broadband radiative transfer 
calculations with the Rapid Radiative Transfer Model for GCMs (RRTMG; Mlawer et al. 1997; Barker et al. 2003; Clough et al. 2005). RRTMG accurately derives shortwave (SW) and longwave (LW) atmospheric fluxes and heating rates. In particular, comparisons between the RRTMG and line-by-line calculations revealed differences in fluxes of less than $1 \mathrm{~W} \mathrm{~m}^{-2}$ and differences in heating rates of less than $0.1 \mathrm{~K} \mathrm{day}^{-1}$ in the troposphere and $0.3 \mathrm{~K} \mathrm{day}^{-1}$ in the stratosphere (Iacono et al. 2008).

RRTMG requires further input, for example, thermodynamic profiles, aerosol information, surface albedo, and surface temperature. Since radiosonde profiles are typically launched at Ny-Ålesund only one time per day, profiles of atmospheric temperature, humidity and pressure are taken from the National Weather Service's National Centers for Environmental Prediction Global Data Assimilation System (GDAS1) dataset (Kanamitsu 1989; see also https://www.ready.noaa.gov/gdas1.php). The model data have a temporal resolution of $3 \mathrm{~h}$. Model profiles are extended up to $30 \mathrm{~km}$ with mean monthly climatological profiles based on radiosonde observations from Ny-Ålesund (Maturilli and Kayser 2016, 2017). The thermodynamic profiles are then linearly interpolated to the 30-s grid of the microphysical properties. The temperature profile is further modified by setting the measured $10-\mathrm{m}$ temperature to the lowest full model level, which is around 10-m height. The surface temperature is estimated from the $\mathrm{LW}$ upward $\left(F_{\mathrm{LW}_{\mathrm{obs}}}^{\uparrow}\right)$ and LW downward $\left(F_{\mathrm{LW}_{\mathrm{obs}}}^{\downarrow}\right)$ BSRN radiation observations: $T_{s}=\left[\left(F_{\mathrm{LW}_{\mathrm{obs}}}^{\uparrow}-\epsilon F_{\mathrm{LW}_{\mathrm{obs}}}^{\downarrow}\right) /(\varepsilon \sigma)\right]^{1 / 4}$. To calculate the surface temperature, a surface emissivity $\epsilon$ has to be assumed. Rees (1993) analyzed infrared emissivities of Arctic land-cover types based on observations from Svalbard. The surface material that Rees (1993) has analyzed and that most likely corresponds to the surface type at Ny-Ålesund is moss with an emissivity of 0.963 . We use this value in case of a snow-free surface. In case of high solar surface albedo (snow-covered surface), the surface emissivity is set to 0.996 . Highly temporally resolved IWV information from the MWR is used to scale the humidity profile. In this way, temporal variations in water vapor and surface and near-surface temperature on the subminute scale are taken into account.

In RRTMG, the SW surface albedo is separated into an albedo for the direct SW radiation and for the diffuse SW radiation. The SW CRE is thus not only driven by the cloud properties but also by the different surface albedo conditions under clear and cloudy sky, respectively. The direct and the diffuse albedo are calculated from the measured upward and downward shortwave fluxes at the surface following the approach of Yang et al. (2008). First, a daily mean diffuse albedo $\alpha_{\text {dif }}^{\text {day }}$ is computed from those measurements for which the downward SW flux is dominated by the diffuse flux. To this end, we selected cases where the fraction of the downward diffuse SW flux to the total downward SW flux is larger than 0.98. On a few days with persistent clear-sky conditions, this condition is not fulfilled and daily mean values for the diffuse albedo are estimated by linear interpolation. The calculation of a daily mean value is reasonable since the diffuse SW albedo does not depend on solar zenith angle (SZA). In addition to variations in the surface characteristics, for example, in vegetation or snow cover and age, variations in the daily diffuse albedo may be also a result of the applied sampling method. For certain samples, the downward diffuse fluxes still contain up to $2 \%$ of the direct-beam fluxes inducing uncertainties in the derived diffuse albedo. In a second step, values for the direct albedo $\alpha_{\text {dir }}$ are calculated from the measured SW flux components and the corresponding daily mean diffuse albedo $\alpha_{\text {dif }}^{\text {day }}$ by $\alpha_{\text {dir }}=F_{\text {SWdir }}^{\uparrow} / F_{\text {SWdir }}^{\downarrow}$, with $F_{\text {SWdir }}^{\uparrow}=F_{\text {SW }}^{\uparrow}-\alpha_{\text {dif }}^{\text {day }} F_{\text {SWdif }}^{\downarrow}$. The $F_{\text {SWdif }}^{\downarrow}, F_{\text {SWdir }}^{\downarrow}$, and $F_{\text {SW }}^{\uparrow}$ are the measured downward diffuse, downward direct, and upward SW surface fluxes.

To describe the dependence of the direct albedo on the cosine of the SZA $\theta$, a polynomial function of the form $\alpha_{\mathrm{dir}}=(1+\mathrm{c} 1) /[1+\mathrm{c} 2 \cos (\theta)]$ has been fitted to the calculated direct albedo values. The fit has been performed separately for each month and for each diffuse albedo class in that month. Figure 1 exemplarily shows the computed direct albedo values for all cases in May 2017 where $0.8<\alpha_{\text {dif }}^{\text {day }}<0.9$ (Fig. 1, left) and for all cases in June 2017 where $\alpha_{\text {dif }}^{\text {day }}<0.3$ (Fig. 1, right). The direct albedo can thus be calculated from the daily mean diffuse albedo, the corresponding polynomial fit for the corresponding month and the cosine of the SZA. The RMSE of the polynomial fit is typically smaller than 0.05 . Only for the transition periods between snowcovered and snow-free surfaces $\left(0.3<\alpha_{\text {dif }}^{\text {day }}<0.7\right)$, uncertainties are larger. A difficulty here is that only a few cases are available to calculate the fit-for example, for the class $0.3<\alpha_{\text {dif }}^{\text {day }}<0.5$ only 7 days in total are available. Instead of a monthly fit, a fit that is based on all cases with $0.3<\alpha_{\text {dif }}^{\text {day }}<0.5$ is thus used instead (not shown). Even though these cases exhibit a high uncertainty in the direct albedo (RMSE of 0.11), they are also rare and thus do not have a strong impact on the estimation of the CRE. In fact, $96 \%$ of the days exhibit a daily mean diffuse albedo smaller than 0.3 or larger than 0.7 . Note that the albedo measurements are representative for the tundra surface type around $\mathrm{Ny}$-Ålesund but not for the larger domain including mountains, fjord, moraines, and rivers.

The radiative transfer model requires also information on aerosol optical thickness, single-scattering albedo and asymmetry parameter. For the latter two, values for 

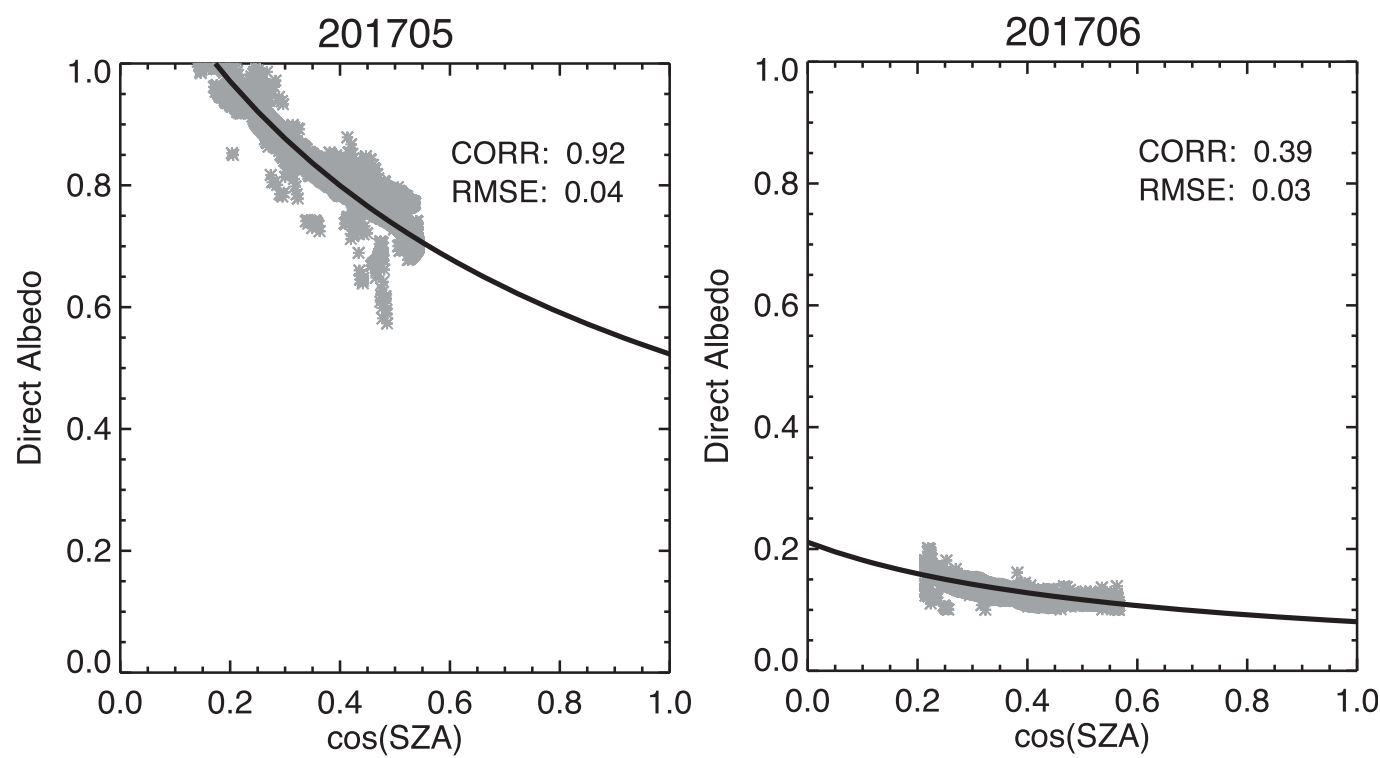

FIG. 1. Direct albedo as a function of cosine of solar zenith angle: (left) all cases (gray asterisks) in May 2017 for which $0.8<\alpha_{\text {dif }}^{\text {day }}<0.9$ and (right) all cases in June 2017 for which $\alpha_{\text {dif }}^{\text {day }}<0.3$. Correlation and RMSE of the polynomial fit (black line) are also shown. See the text for more details.

maritime clean aerosol are applied that were computed from the Optical Properties of Aerosols and Clouds (OPAC) database (Hess et al. 1998). With a single-scattering albedo of $>0.98$, this type of aerosol seems to best represent the conditions at Ny-Ålesund. Since daily values of aerosol optical depth are not available, we use a climatological mean value based on 12-year-long observations of the Aerosol Robotic Network (AERONET; Holben et al. 1998) at Hornsund. The aerosol optical thickness is then vertically distributed following a typical aerosol profile at Ny-Ålesund as observed from Raman lidar measurements. Information on further trace gases other than water vapor are included via standard atmospheric profiles of the subarctic summer and winter reference atmospheres (Anderson et al. 1986). Carbon dioxide is assumed to have a constant concentration of $400 \mathrm{ppm}$.

Since the radiative transfer calculations are performed twice, with clouds when present and without clouds, the impact of clouds on the atmospheric longwave and shortwave fluxes can be directly calculated as the difference between all-sky and clear-sky fluxes. In the following, we define the CRE as the difference of the all-sky and clear-sky net radiative fluxes, that is, downward minus upward component (Mace et al. 2006; Rossow and Zhang 1995). The CRE can be calculated for the SW, for the $\mathrm{LW}$, and as a net effect that is the sum of the SW and LW parts. The CRE is calculated for the surface (SFC) and the top of the atmosphere (TOA) using the radiation fluxes of the lowest and the highest model layer, respectively. The atmospheric (ATM) CRE is then given as the difference between TOA CRE and SFC CRE. Note that the CRE is calculated solely from the modeled radiative fluxes. The observed BSRN LW and SW surface fluxes are only used for the evaluation of the modeled fluxes.

\section{Evaluation of simulated surface radiative fluxes and uncertainties in retrieved surface CRE}

Except for June 2016, in all of the months, the data coverage of the Cloudnet target categorization product is greater than $80 \%$, and in more than four-fifths of the time it is even greater than $90 \%$ (not shown). In June 2016 , the Cloudnet data coverage is only $65 \%$ since the cloud radar measurements started in mid-June. For the radiative transfer calculations additional measurements are required. In particular, the availability of MWR LWP observations pose a constraint here that further reduces the number of available profiles. To calculate the monthly CRE, we first calculate 10-min time averages from the radiative transfer calculations based on the 30-s single profiles. The 10-min intervals are subsequently used to calculate hourly averages. From the hourly averages, daily mean values are calculated if at least $80 \%$ of the data are available. The daily mean values are averaged to produce the monthly mean values.

To assess how representative this dataset of the available 30 -s profiles for the whole time period is, we calculated 


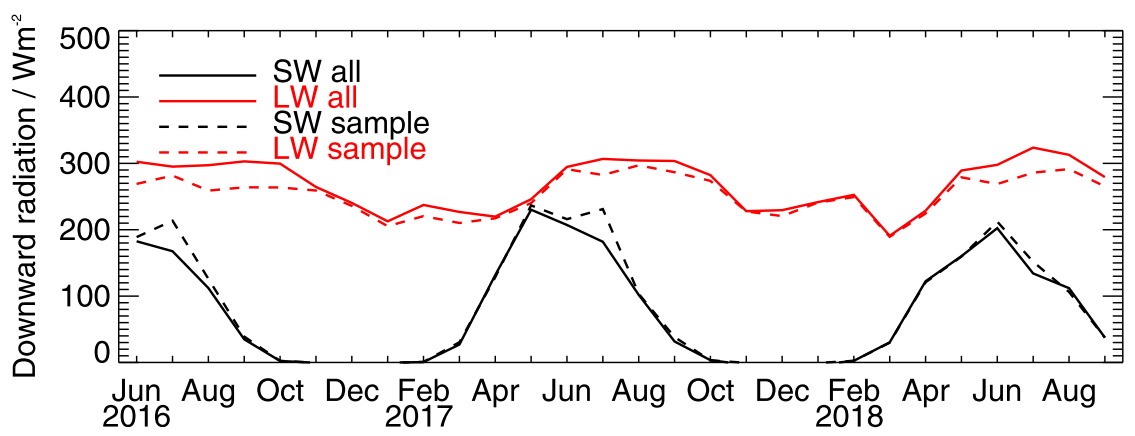

FIG. 2. Monthly mean measured BSRN SW (black lines) and LW (red lines) surface downward radiation for all times (solid lines) and for the subsample for which radiative transfer simulations are available (dashed lines).

monthly mean values of SW and LW downward radiation from the BSRN data using the same sampling strategy. We did the analysis twice, once with all available BSRN data for the time period June 2016 to September 2018 and once eliminating all BSRN data points where no concurrent radiative transfer simulation is available (Fig. 2). In general, the subsample nicely reproduces the monthly mean SW and LW values. However, in particular in the summer months, and for SW radiation particularly in July, larger differences of up to 40 and $50 \mathrm{~W} \mathrm{~m}^{-2}$ in the $\mathrm{LW}$ and SW mean values, respectively, can be observed. In these cases, LW downward surface radiation is underestimated and SW downward surface radiation is overestimated implying that cloudy or optically thick cloud cases are missed in our data sample. These results also have implications for our CRE estimates. Since we underrepresent cloudy situations in our data sample, the CRE is likely underestimated in these months.

The simulated surface downward radiative fluxes have been subsequently compared with observed ones (Fig. 3). To better compare the 1D radiative transfer calculations to the hemispheric radiation observations, the fluxes have been averaged over $10 \mathrm{~min}$. When taking into account both cloudy and clear-sky profiles in the 10-min averages (Fig. 3a), we find only a small bias in the SW and LW downward fluxes of -3.1 and $-0.2 \mathrm{~W} \mathrm{~m}^{-2}$, respectively. The interquartile range (IQR) of the differences is $43.5 \mathrm{~W} \mathrm{~m}^{-2}$ for the $\mathrm{SW}$ and $12.2 \mathrm{~W} \mathrm{~m}^{-2}$ for the $\mathrm{LW}$ flux. A similar magnitude of differences between simulated and observed surface downward fluxes has been found by Shupe et al. (2015), who also used cloud properties retrieved from ground-based remote sensing observations at Barrow in a radiative transfer model.

Performing the analysis for clear-sky scenes only (Fig. 3b) reveals a small bias $\left(-5.0 \mathrm{~W} \mathrm{~m}^{-2}\right)$ and IQR $\left(6.2 \mathrm{~W} \mathrm{~m}^{-2}\right)$ in the $\mathrm{LW}$. In the $\mathrm{SW}$, bias and IQR are larger. In particular, positive differences larger than $50 \mathrm{~W} \mathrm{~m}^{-2}$ hint at situations in which clouds are in the field of view of the hemispheric broadband radiation measurements but not directly above the cloud radar and ceilometer. Also, shading effects by mountains that are not taken into account in the radiative transfer calculations might lead to an overestimation of the simulated SW surface flux. Still, this is a very good closure and the results are similar to the ones presented by Shupe et al. (2015). With a distribution mode near $0 \mathrm{~W} \mathrm{~m}^{-2}$, the $\mathrm{SW}$ differences are even slightly smaller in our study. To give confidence in the method for representing surface albedo in the radiative transfer calculations, we also compared SW upward fluxes (not shown). Bias and IQR are here 8.8 and $19.5 \mathrm{~W} \mathrm{~m}^{-2}$, respectively, in clear-sky conditions and 2.4 and $13.8 \mathrm{~W} \mathrm{~m}^{-2}$, respectively, in all-sky conditions. The differences in the SW upward and downward fluxes are thus similar in size.

In cloudy cases, differences in LW downward fluxes are small (Fig. 3f). Bias and IQR are only 1.6 and $10.6 \mathrm{~W} \mathrm{~m}^{-2}$, respectively. With a bias and IQR of -9.5 and $54.1 \mathrm{~W} \mathrm{~m}^{-2}$, differences are larger in the SW (Fig. 3e). These differences are a combined result of 3D effects that are not taken into account by the $1 \mathrm{D}$ radiative transfer simulations, a misclassification of the scene (cloudy/cloud-free, cloud type), uncertainties in the assumed direct and diffuse albedo and uncertainties in the cloud microphysical properties themselves. Shupe et al. (2015) found smaller differences in the SW surface downward flux under cloudy conditions, which might be related to a better estimate of the liquid amount in the atmospheric column. In addition to MWR observations, they also include passive infrared radiances, which can reduce the uncertainty in the LWP retrieval when LWP is low (Turner 2007).

To assess the uncertainty in the retrieved surface CRE, we follow the approach by Mace et al. (2006). The variance of the surface CRE $\sigma_{\mathrm{CRE}_{x}}^{2}$ can be expressed as $\sigma_{\mathrm{CRE}_{x}}^{2}=\left(\sigma_{F_{\text {net }, x}}^{2}\right)_{\text {all-sky }}+\left(\sigma_{F_{\text {net }, x}^{2}}^{2}\right)_{\text {clear-sky }}$, with $x$ denoting 
a)


e)



b)

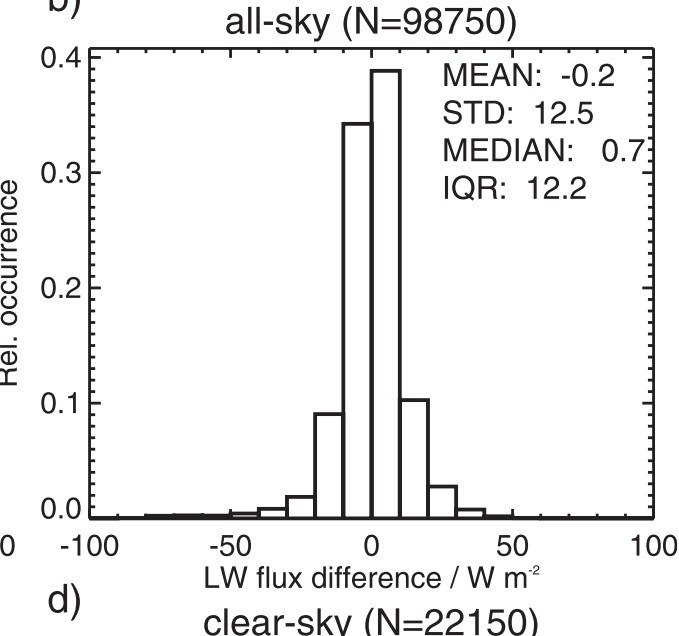

d)

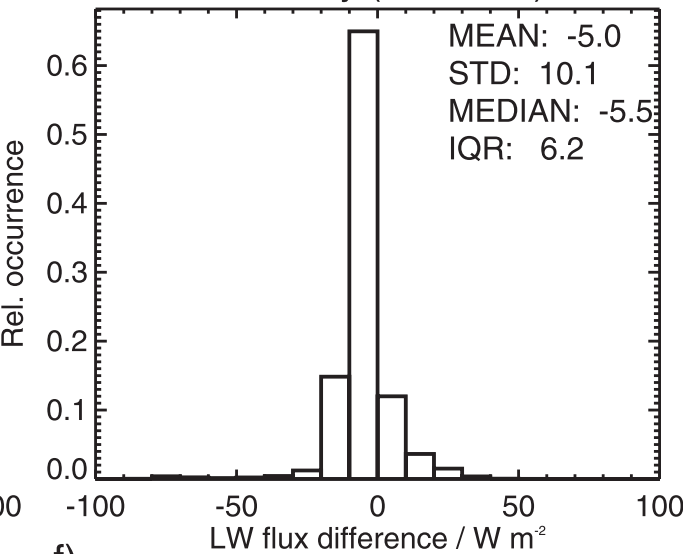

f)



FIG. 3. Histograms of simulated minus observed surface downward radiative fluxes at Ny-Ålesund for (a) SW, all sky; (b) LW, all sky; (c) SW, clear sky; (d) LW, clear sky; (e) SW, cloudy; and (f) LW, cloudy. Fluxes are averaged for a 10 -min time period.

either SW or LW and $\sigma_{F_{\text {net }, x}}^{2}$ being the variance of the net SW or LW fluxes for all-sky and clear-sky conditions. $\sigma_{\mathrm{CRE}_{\text {net }}}^{2}$ can then be expressed as $\sigma_{\mathrm{CRE}_{\mathrm{net}}}^{2}=\sigma_{\mathrm{CRE}_{\mathrm{SW}}}^{2}+$ $\sigma_{\mathrm{CRE}_{\mathrm{LW}}}^{2}$. Values for $\sigma_{F_{\mathrm{net},}^{2}}^{2}$ can be estimated by comparing the simulated net fluxes with the observed ones under all-sky and clear-sky conditions (Fig. 4). From Fig. 4, we find $\left(\sigma_{F_{\text {net }, \text { W }}}\right)_{\text {all-sky }}=51.4 \mathrm{~W} \mathrm{~m}^{-2},\left(\sigma_{F_{\text {net }, \mathrm{LW}}}\right)_{\text {all-sky }}=14.8 \mathrm{~W} \mathrm{~m}^{-2}$, $\left(\sigma_{F_{\text {net }, S w}}\right)_{\text {clear-sky }}=38.6 \mathrm{~W} \mathrm{~m}^{-2}$, and $\left(\sigma_{F_{\text {net,LW }}}\right)_{\text {clear-sky }}=$ $13.1 \mathrm{~W} \mathrm{~m}^{-2}$. These uncertainties represent the uncertainties for an averaging interval of $10 \mathrm{~min}$. Corresponding 

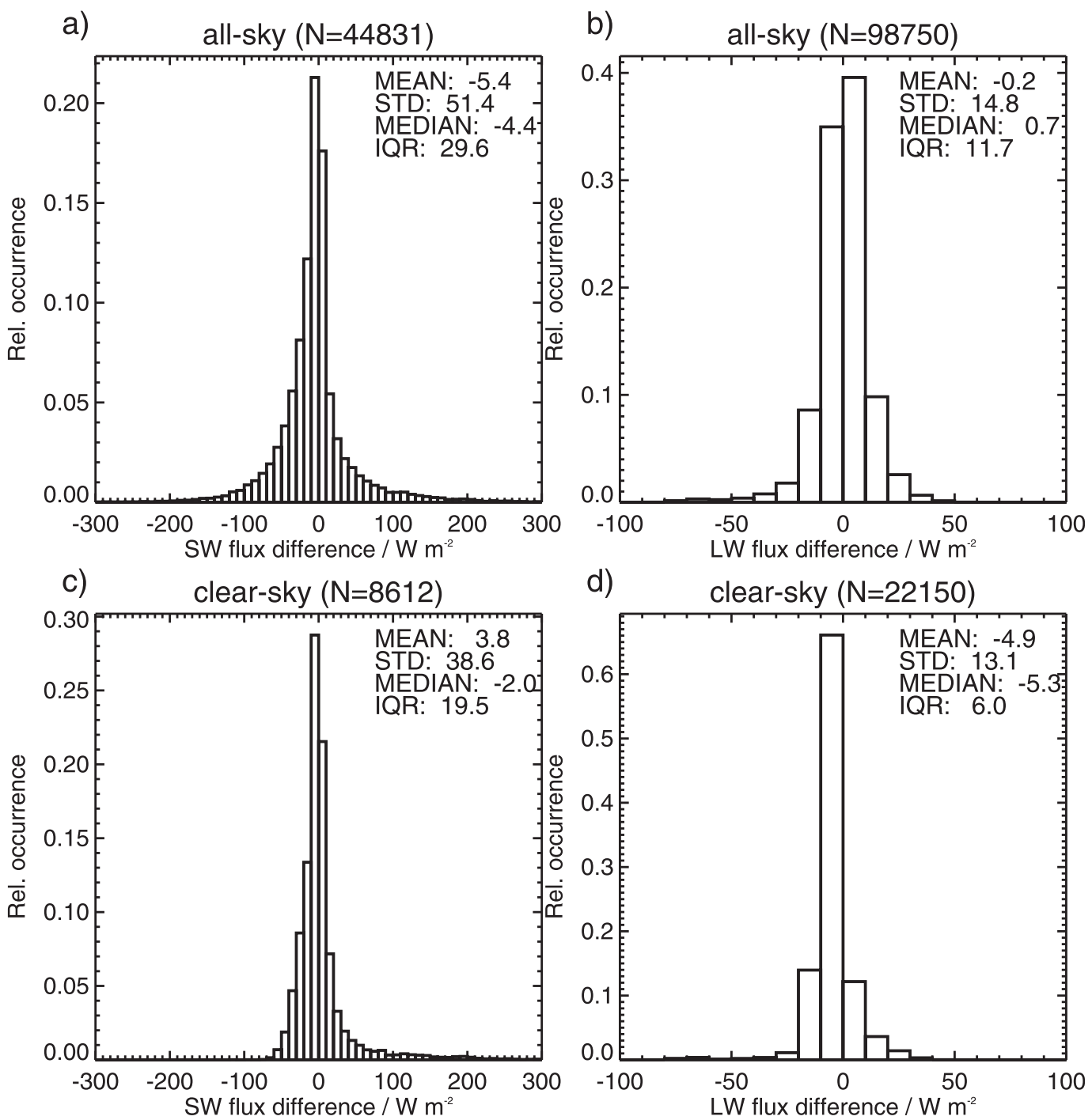

FIG. 4. Simulated minus observed net (downward minus upward) surface radiative fluxes at Ny-Ålesund for (a) SW, all sky; (b) LW, all sky; (c) SW, clear sky; and (d) LW, clear sky.

uncertainties in the surface CRE are thus $64.3 \mathrm{~W} \mathrm{~m}^{-2}$ for the $\mathrm{SW}, 19.8 \mathrm{~W} \mathrm{~m}^{-2}$ for the $\mathrm{LW}$, and $67.3 \mathrm{~W} \mathrm{~m}^{-2}$ for the net CRE (first column in Table 2).

Going from 10-min CRE values to larger averaging times will decrease the uncertainty in the mean value of the CRE, that is, $\overline{\mathrm{CRE}_{x}}$. The variance of $\overline{\mathrm{CRE}_{x}}$ is then given as $\sigma_{\overline{\mathrm{CRE}}_{x}}^{2}=\sigma_{\mathrm{CRE}_{x}}^{2} / N$, with $N$ being the number of realizations composing $\overline{\mathrm{CRE}_{x}}$. Note that we assume that these realizations are uncorrelated. For the calculation of the CRE, the 10-min intervals are used to calculate first hourly and then daily mean CRE values if always $80 \%$ of the data are available. In these cases, the uncertainty in the retrieved CRE is further reduced to the values shown in Table 2. Depending on how many days are included in the calculation of the monthly CRE, the uncertainty ranges between 0.4 and $0.5(\mathrm{LW})$ and 1.2 and $1.7 \mathrm{~W} \mathrm{~m}^{-2}$ (SW and net). Note that these uncertainties do not include the uncertainties associated with the subsample (Fig. 2). The overall uncertainty in the CRE estimate is thus likely larger because of sampling error.

\section{Cloud radiative effect}

Various factors influence the CRE, for example, the cloud properties themselves, solar surface albedo, and solar zenith angle. We thus first have a look on the monthly statistics of SZA, solar surface albedo, and frequency of occurrence (FOC) of hydrometeors, along with LWP and IWP for Ny-Ålesund (Fig. 5). 
TABLE 2. Approximate uncertainty in the surface CRE $\left(\mathrm{W} \mathrm{m}^{-2}\right)$ for certain averaging times and assuming that at least $80 \%$ of the data in the averaging interval are available. The uncertainty in the monthly CRE is given as a range depending on the number of days included, e.g., 30 or 15 .

\begin{tabular}{lcccc}
\hline \hline & 10-min & Hourly & Daily & Monthly \\
\hline CRE $_{\text {SW }}$ & 64.3 & 28.8 & 6.4 & $1.2-1.7$ \\
CRE $_{\text {LW }}$ & 19.8 & 8.9 & 2.0 & $0.4-0.5$ \\
CRE $_{\text {net }}$ & 67.3 & 30.1 & 6.7 & $1.2-1.7$ \\
\hline
\end{tabular}

Figure 5a depicts the range of daily minimum and maximum values of SZA in each month; for the other variables, boxplots of the daily mean values are shown for each month (Figs. 5b-e). Note that for calculating the FOC of hydrometeors we check whether hydrometeors occur anywhere in the atmospheric column. When SZAs are large, the SW incoming solar radiation at the TOA is small. Between October and February, the incoming solar radiation is close to zero at Ny-Ålesund.
From the end of October to the end of February, the sun is below the horizon. Maximum insolation is reached in June with a minimum in SZA of about $55^{\circ}$.

As mentioned before, the solar surface albedo, that is, here simply the ratio of upward and downward surface SW flux, shows two states. Large values of typically more than 0.8 are found in late winter and spring, and low values of less than 0.15 in summer (June-August). The transition periods between snow-covered surface and bare tundra in May/June and September/October reveal a high variability in daily mean values of surface albedo and also a high variability from year to year (Maturilli et al. 2015). In September 2016 and 2017, the surface was still snow free, whereas in September 2018 snow already covered the ground. Relative to 2017, the transition from high to low surface albedo values started one month earlier in May, resulting in a completely snow-free surface already in June.

From the FOC of hydrometeors (Fig. 5c) we find that clouds frequently occur over Ny-Ålesund with a monthly

a)

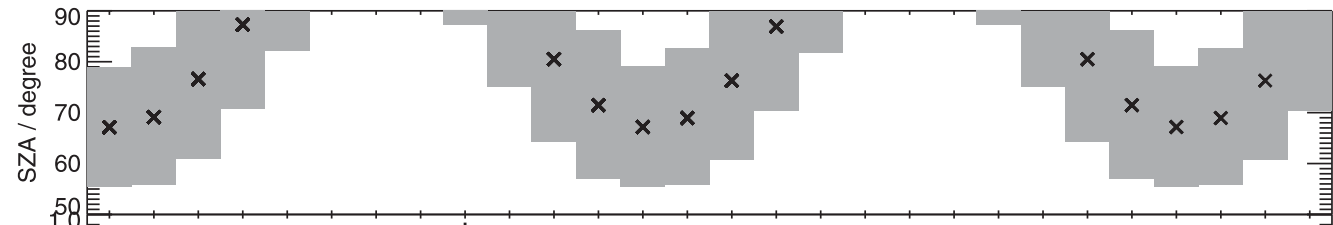

b)


FIG. 5. (a) Range of daily minimum and maximum values of solar zenith angle (gray box) with mean monthly value indicated by an "x." Also shown are boxplots of daily mean values of (b) solar surface albedo, (c) frequency of occurrence of any hydrometeors (black) and liquid droplets (grey) in atmospheric column, (d) nonzero liquid water path, and (e) nonzero ice water path. The box indicates the 25th and 75th percentiles, the whiskers show the minimum and maximum, the horizontal line inside the box is the median, and the $\mathrm{x}$ indicates the mean. 


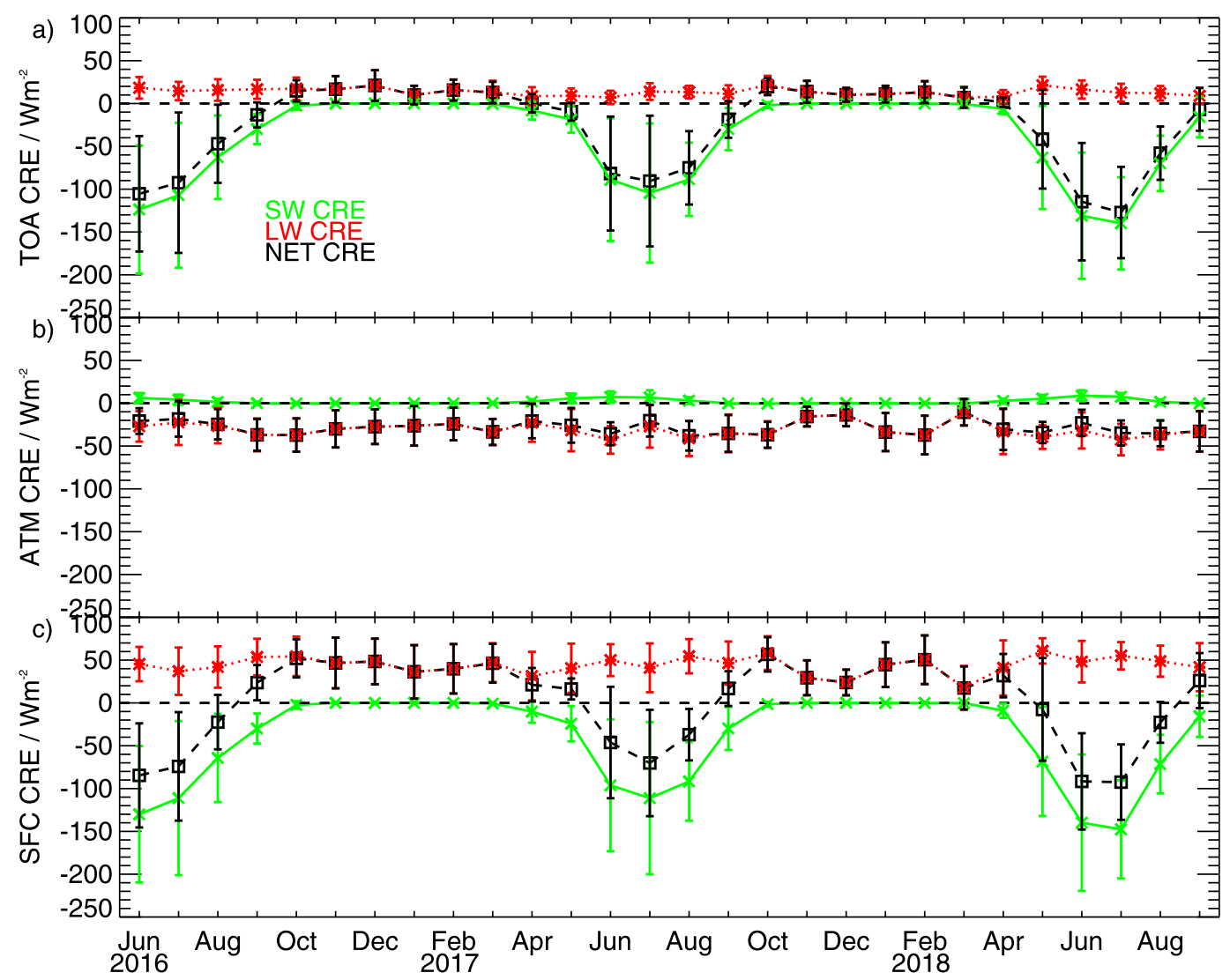

FIG. 6. Monthly mean SW (solid green line), LW (dotted red line), and net (dashed black line) cloud radiative effect at Ny-Ålesund calculated from the RRTMG simulations for (a) the top of the atmosphere, (b) the atmosphere, and (c) the surface. The error bars indicate the standard deviation of the daily mean values.

median FOC of generally greater than $70 \%$. This has already been shown for the first year of radar observations by Nomokonova et al. (2019). Clear-sky days are rare at Ny-Ålesund. In March 2018, on several consecutive days no clouds were observed resulting in an exceptionally low monthly median FOC of clouds of only $24 \%$. When looking at the FOC of liquid in the atmospheric column, a seasonal cycle becomes visible with lowest monthly median values of $20 \%$ between late autumn and early spring and largest values of up to $80 \%$ in summer.

Similar to the FOC of liquid, the daily mean values of LWP for days with LWP $>0 \mathrm{~g} \mathrm{~m}^{-2}$ show generally a seasonal cycle. In summer, daily mean LWP values range from about 10 to more than $100 \mathrm{~g} \mathrm{~m}^{-2}$; in winter and early spring, monthly median values of LWP are typically below $10 \mathrm{~g} \mathrm{~m}^{-2}$. Exceptions are January and February 2018 with higher median values of 12 and $20 \mathrm{~g} \mathrm{~m}^{-2}$, respectively, and higher mean values of 30 and $50 \mathrm{~g} \mathrm{~m}^{-2}$, respectively. The seasonal cycle of IWP is less pronounced. Maximum values predominantly occur from autumn to spring although in 2017 and 2018 a large month-to-month variability can be observed.

\section{a. Surface CRE}

The time series of the resulting monthly mean values of the CRE for the surface, the atmosphere and the top of the atmosphere are depicted in Fig. 6. At the surface (Fig. 6c), clouds lead to an LW warming typically around $50 \mathrm{~W} \mathrm{~m}^{-2}$ with daily variations of up to $40 \mathrm{~W} \mathrm{~m}^{-2}$. In principle, the LW CRE follows the seasonal cycle of FOC of liquid and LWP with largest values in those months in which also the FOC of liquid and LWP is high. With an LW SFC CRE of 20-30 $\mathrm{W} \mathrm{m}^{-2}$, November and December 2017, as well as March 2018, show the lowest values in LW SFC CRE. In these three months, lowest values of FOC of clouds $(75 \%, 62 \%$, and $22 \%$, respectively; all median values) and lowest values of monthly median LWP (3, 2, and $3 \mathrm{~g} \mathrm{~m}^{-2}$, respectively) can be found.

During polar day, clouds strongly cool the surface in the SW with a cooling of more than $-100 \mathrm{~W} \mathrm{~m}^{-2}$ in the 
summer months. Relative to the LW CRE, the daily variability is much larger, which is also due to the large variability in SZA. The SW CRE not only depends on the cloud properties and the incoming solar radiation but also on the surface albedo. For example, in May 2018, the SFC SW CRE is about 7 times as large $\left(-70 \mathrm{~W} \mathrm{~m}^{-2}\right)$ when compared with May $2017\left(-10 \mathrm{~W} \mathrm{~m}^{-2}\right)$. This is due not only to the higher occurrence of clouds and the higher occurrence of liquid but also to the much lower surface albedo in that month. Also, in April, when already a significant amount of solar radiation is available, the SW CRE is still limited because of the high surface albedo values.

The net SFC CRE, that is, the sum of the LW and SW CRE, is thus positive from September to April/May and negative in June, July, and August. The early decrease of surface albedo in May 2018 led to a slight net cooling in that month. Averaging the LW, SW, and net SFC CRE over the whole year of 2017 results in annual average values of $41.6,-30.5$, and $11.1 \mathrm{~W} \mathrm{~m}^{-2}$, respectively. Thus, overall, clouds still lead to a warming at the surface at Ny-Ålesund. Multiyear observations are required to assess the year-to-year variability of the annual cloud radiative effect in the future.

Relative to other sites in the Arctic, the LW SFC CRE is slightly larger at Ny-Ålesund. Dong et al. (2010), for example, analyzed the SFC CRE at Barrow $\left(71^{\circ} \mathrm{N}\right)$ and found an annual average value for the SFC LW CRE of about $31 \mathrm{~W} \mathrm{~m}^{-2}$. They also set their results into context to SHEBA (Intrieri et al. 2002b,a) and other regions in the Arctic (Wang and Key 2005). They found that the LW SFC CRE does not significantly change over the Arctic, with values ranging between 30 and $40 \mathrm{~W} \mathrm{~m}^{-2}$. With an annual average value of $41.6 \mathrm{~W} \mathrm{~m}^{-2}$, also Ny-Ålesund fits into this estimate. Cox et al. (2012) approximated the LW SFC CRE by the difference of the all-sky and clear-sky LW downward fluxes and analyzed 3 years of data from Eureka and Barrow. For Eureka, results were very different, with an LW surface cloud forcing of only $27 \mathrm{~W} \mathrm{~m}^{-2}$. The weaker LW CRE is partly related to differences in cloud fraction and cloud altitude (Cox et al. 2012). Differences in the LW CRE may be also due to temperature and water vapor differences between the sites since these variables also affect the LW CRE (Cox et al. 2015). Regarding the SW SFC CRE, results differ for the different stations and regions due to different surface albedo and SZA conditions. Relative to Barrow, the annual average SW SFC CRE is similar $\left(-26.2 \mathrm{~W} \mathrm{~m}^{-2}\right)$ to the one observed at $\mathrm{Ny}$-Ålesund. However, because of the larger LW SFC CRE, the net SFC CRE is larger at Ny-Ålesund than at Barrow $\left(4.5 \mathrm{~W} \mathrm{~m}^{-2}\right)$. In general, with increasing latitude, LW cloud warming becomes more important
(Dong et al. 2010; Kay and L'Ecuyer 2013). Whether LW warming outweighs SW cooling also depends on the surface albedo. At Summit, located at $72.6^{\circ} \mathrm{N}$ and thus farther south than Ny-Ålesund, the annual average net SFC CRE is $33 \mathrm{~W} \mathrm{~m}^{-2}$ (Miller et al. 2015) and thus is almost 3 times that at Ny-Ålesund. This is due to high surface albedo at Summit throughout the entire year limiting the SW cooling effect of clouds at the surface, even at low SZAs.

\section{b. Atmospheric CRE and CRE at the top of the atmosphere}

Other studies (e.g., Miller et al. 2015; Dong et al. 2010) based their analysis purely on surface radiation observations and clear-sky simulations, but the analysis of the CRE was limited to the surface. By making use of a radiative transfer model, we can easily assess the CRE at the TOA and for the atmosphere (Figs. 6a,b).

Since clouds lead to a reduction of emitted LW radiation to space, the LW TOA CRE is positive and in the range of $7-22 \mathrm{~W} \mathrm{~m}^{-2}$. This $\mathrm{LW}$ warming at the TOA is smaller than the LW SFC warming since clouds and, in particular, the liquid parts of the cloud are located in lower atmospheric layers where the difference between the temperature of the emitting clouds and of the surface is less pronounced. Because of enhanced reflected solar radiation by clouds, the SW TOA CRE is negative during polar day and is of the same order of magnitude as the SW SFC cooling. Since the LW TOA CRE does not exceed $22 \mathrm{~W} \mathrm{~m}^{-2}$, the net TOA CRE is negative in summer and September. For 2017, the annually averaged net TOA CRE is $-16.1 \mathrm{~W} \mathrm{~m}^{-2}$.

The ATM CRE describes the how the radiation balance of the atmosphere is modified by clouds. For the radiation balance of the atmosphere, fluxes into the atmospheric layer have a positive contribution (downward fluxes at TOA, upward fluxes at the SFC), fluxes out of the layer have a negative contribution (upward fluxes at TOA, downward fluxes at SFC). The ATM CRE is thus the difference between the radiation balance of the atmosphere in cloudy conditions minus the radiation balance in clear-sky conditions. For the atmosphere, we find a small SW cloud-induced warming with a maximum of $8 \mathrm{~W} \mathrm{~m}^{-2}$ in June. This is mainly driven by a reduced downward SW surface flux (a sink term in the radiation balance of the atmosphere) under cloudy conditions. This warming effect by clouds is partly compensated by an increased upward SW flux at the TOA (sink term) and a reduced upward SW flux at the surface (source term) relative to clear-sky conditions. The LW ATM CRE is negative in all months with monthly mean values between -10 and $-40 \mathrm{Wm}^{-2}$. This LW ATM cooling basically mirrors the LW SFC warming but with 




FIG. 7. Longwave surface CRE as a function of LWP from hourly mean values. The box indicates the 25 th and 75 th percentiles, the whiskers show the minimum and maximum, the horizontal line inside the box is the median, and the $\mathrm{x}$ indicates the mean. Note the increasing LWP bin sizes of $5,10,25,50$, and $100 \mathrm{~g} \mathrm{~m}^{-2}$.

smaller absolute values. The longwave cooling effect of clouds on the atmosphere is due to the enhanced downward LW surface flux under cloudy conditions, which can only partly be compensated by the decreased upward LW flux at the TOA. Since the SW ATM CRE is relatively small, the net ATM CRE is dominated by the LW ATM CRE resulting in an annual average value of $-27.2 \mathrm{~W} \mathrm{~m}^{-2}$.

\section{Sensitivity of surface CRE}

Variations in the atmospheric state, cloud properties, surface albedo, and SZA all contribute to the variability in the CRE as indicated, for example, by the variability of the daily mean values in Fig. 6 . To better understand the impact of the different variables on the CRE at Ny-Ålesund, we take a closer look at the SFC CRE and its dependency on LWP, IWP, and SZA.

\section{a. Liquid water path}

The monthly mean time series of LW CRE and LWP already revealed that LWP plays a substantial role in LW SFC warming. Figure 7 shows the LW SFC CRE as a function of the LWP based on hourly mean values. The variability of the LW SFC CRE in each LWP class is due to variations of LWP within the class, variations in ice clouds that might occur at the same time, variations in atmospheric temperature and different cloud cover values within the 1-h interval. In particular, this variability in LW SFC CRE is large (IQR of $\sim 60 \mathrm{~W} \mathrm{~m}^{-2}$ ) for LWP values smaller than $5 \mathrm{~g} \mathrm{~m}^{-2}$, which occur mainly as a result of variations in IWP. With increasing LWP and thus increasing cloud LW emissivity, the LW SFC CRE exponentially increases and asymptotically reaches a value of about $75 \mathrm{~W} \mathrm{~m}^{-2}$ when cloud emissivity becomes 1. The small decrease of the LW SFC CRE at very high LWP values is most likely related to the IWV for these cases. Cox et al. (2015) demonstrated that the LW CRE also depends on relative humidity. Based on radiative transfer simulations and observations from Barrow and Eureka, they showed that at constant temperature, the LW CRE decreases with increasing IWV. For cases with LWP $>300 \mathrm{~g} \mathrm{~m}^{-2}$, we found a strong increase in IWV (not shown) explaining the reduced LW SFC CRE.

Figure 7 clearly shows that LWP is a dominant driver of the LW SFC CRE. Similar results have also been found by Miller et al. (2015) for Summit with an asymptote mean value of $85 \mathrm{~W} \mathrm{~m}^{-2}$. Since this value depends on the site-specific cloud characteristics like base height and temperature (Shupe and Intrieri 2004) as well as on the amount of IWV (Cox et al. 2015), it can be different for different sites, for example, $65 \mathrm{~W} \mathrm{~m}^{-2}$ in the Beaufort Sea (Shupe and Intrieri 2004) and between 70 and $80 \mathrm{~W} \mathrm{~m}^{-2}$ during the Arctic Summer Cloud Ocean Study near $87.5^{\circ} \mathrm{N}$ (Sedlar et al. 2011). Only for Barrow an unusual linear increase without saturation effect has been observed by Dong et al. (2010).

The SW SFC CRE is a function of LWP and SZA, and also depends on the surface albedo. For high values of surface albedo, that is, over sea ice and snow-covered ground, this dependency has also been analyzed by Shupe and Intrieri (2004) and Miller et al. (2015), respectively. Since at Ny-Ålesund, two preferred albedo states occur (Fig. 5b), we performed the analysis for diffuse surface albedo values $>0.8$ and for values $<0.3$ (Fig. 8). In general, the magnitude of SW SFC CRE increases with decreasing SZA. At high SZA $\left(\mathrm{SZA}>75^{\circ}\right)$, 
a)

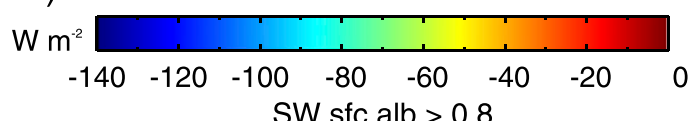

b)
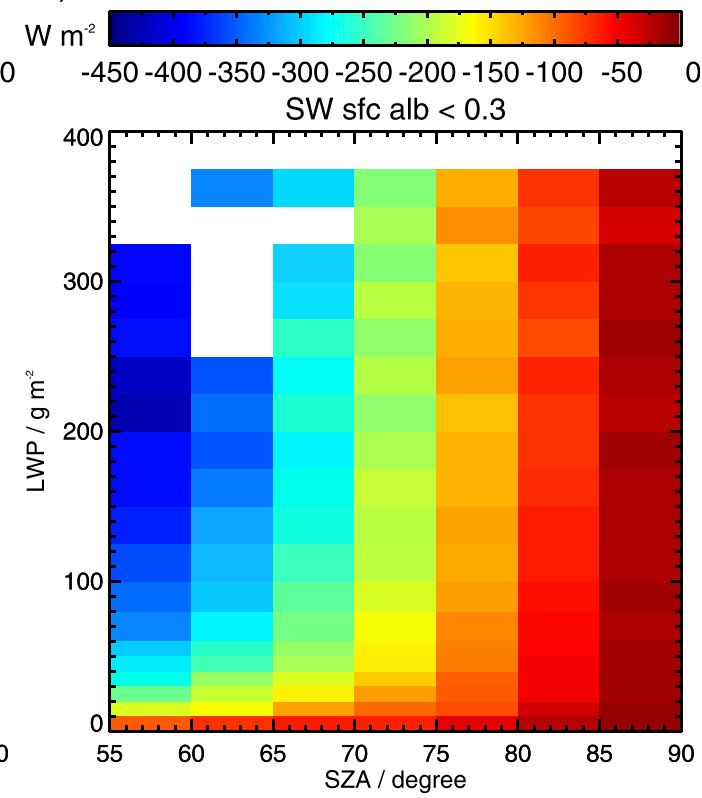

FIG. 8. Shortwave surface CRE as a function of LWP and SZA for diffuse surface albedo values (a) $>0.8$ and (b) $<0.3$. The analysis is based on hourly mean values.

the SW SFC CRE is independent of the LWP; for lower SZAs $\left(\mathrm{SZA}<75^{\circ}\right)$, the SW cloud cooling increases with increasing LWP. The functional dependency of the SW SF CRE on LWP and SZA is similar to the one found by Miller et al. (2015) for the Summit station, but the absolute values are very different. In the case of high diffuse surface albedo (Fig. 8a), the SW SFC CRE decreases to $-140 \mathrm{Wm}^{-2}$. Miller et al. (2015) found a maximum cooling of only $-65 \mathrm{~W} \mathrm{~m}^{-2}$. The larger SW SFC cooling effect that we found might be related to differences in surface albedo. Miller et al. (2015) estimated the surface albedo from the SW upward and downward fluxes under clear-sky conditions, that is, a "blue-sky albedo," and used this albedo in the radiative transfer calculations. Even for low SZA, their clear-sky albedo estimate is still larger than 0.8. For Ny-Ålesund, we separated the blue-sky albedo into the diffuse and direct component and included these values in the RRTMG calculations. In case of a high diffuse surface albedo (e.g., 0.8-0.9) and low SZA, the direct albedo is lower than the diffuse one (Fig. 1). Since less SW radiation is reflected in clear sky, the SW SFC CRE is enhanced. However, it remains unclear whether the differences between Ny-Ålesund and Summit are due to the different methods for surface albedo or due to environmental factors, for example, different snow characteristics or more ice clouds present over Ny-Ålesund. For low diffuse surface albedos (Fig. 8b), the dependency of SW SFC CRE on LWP and SZA is similar except that the magnitude of SW SFC CRE is higher by up to a factor of 3 for low SZAs. For SZA $<60^{\circ}$ and LWP $>200 \mathrm{~g} \mathrm{~m}^{-2}$, mean values of SW SFC CRE are below $-400 \mathrm{~W} \mathrm{~m}^{-2}$.

The resulting net SFC CRE as a function of LWP and SZA is depicted in Fig. 9. For diffuse surface albedo values $>0.8$ (Fig. 9a), liquid-containing clouds typically have a net warming effect in case of SZA $>65^{\circ}$. The largest net cloud warming of up to $79 \mathrm{~W} \mathrm{~m}^{-2}$ can be found at the highest SZA. For lower SZAs, the SW cooling cannot be compensated by the LW warming resulting in a net cooling effect with values lower than $-40 \mathrm{~W} \mathrm{~m}^{-2}$. For the reasons discussed in the previous section, our results for the net SFC CRE differ from the results by Miller et al. (2015) who found a positive net SFC CRE under all SZAs.

Also, for low diffuse surface albedo conditions, the net surface CRE can be either positive or negative depending on the LWP and the SZA. (Fig. 9b). At SZA $>85^{\circ}$, where SW surface cooling by clouds is only $-20 \mathrm{~W} \mathrm{~m}^{-2}$, a positive net surface CRE of $55-65 \mathrm{~W} \mathrm{~m}^{-2}$ can be found. Also for SZA between $80^{\circ}$ and $85^{\circ}$ and LWP $<250 \mathrm{~g} \mathrm{~m}^{-2}$, the net SFC CRE is still positive. For smaller SZAs, SW cloud cooling becomes dominant and increases with decreasing SZA and with increasing LWP. Mean net CRE values below $-300 \mathrm{~W} \mathrm{~m}^{-2}$ can thus occur for cases with $\mathrm{SZA}<60^{\circ}$ and $\mathrm{LWP}>150 \mathrm{~g} \mathrm{~m}^{-2}$.

\section{b. Ice water path}

When both liquid water and ice are present in the atmosphere, LW SFC CRE and SW SFC CRE are 
a)


b)



SW sfc alb $<0.3$

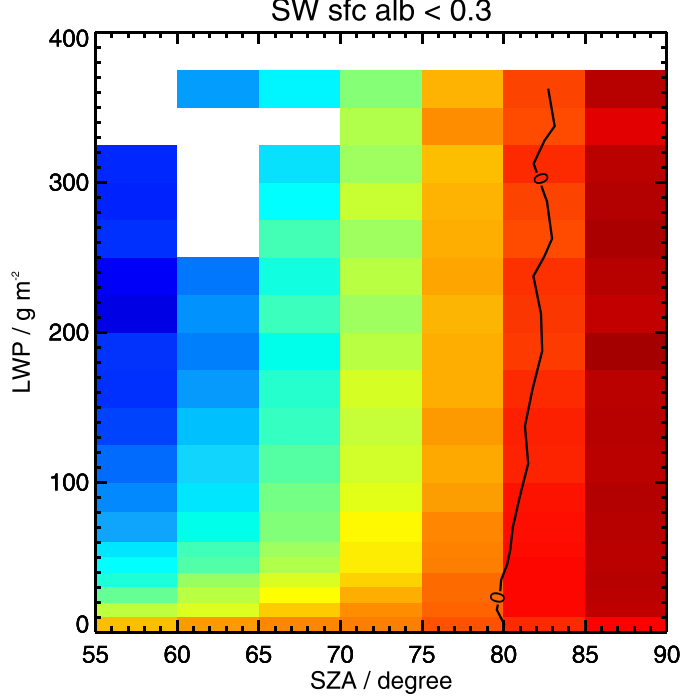

FIG. 9. As in Fig. 8, but for net surface CRE. The $0 \mathrm{~W} \mathrm{~m}^{-2}$ isoline is shown as a black line.

dominated by the amount of liquid water. To see the impact of ice clouds on the CRE, Fig. 10 depicts the SFC CRE as a function of IWP for cases with low amounts $\left(<5 \mathrm{~g} \mathrm{~m}^{-2}\right)$ of liquid water in the atmospheric column. In the LW, a similar asymptotic behavior of the CRE as for liquid-containing clouds can be observed. The asymptote value of $75 \mathrm{~W} \mathrm{~m}^{-2}$ is reached around an IWP of $100 \mathrm{~g} \mathrm{~m}^{-2}$. For the SW, we again distinguish between high and low diffuse surface albedo values. In case that the diffuse surface albedo is larger than 0.8, SW SFC cooling is from -10 to $-20 \mathrm{~W} \mathrm{~m}^{-2}$ for IWP values larger than $25 \mathrm{~g} \mathrm{~m}^{-2}$. Variations in SW SFR CRE within an IWP class are due to the various SZAs under which these clouds occur. As for liquid-containing clouds, the SW SFC CRE for ice clouds is small for high SZAs and does not show a pronounced sensitivity toward IWP (not shown). With decreasing SZA, the sensitivity to IWP increases.

For diffuse surface albedo values lower than 0.3 , the SW SFC cooling effect by clouds is much stronger, that is, up to $-360 \mathrm{~W} \mathrm{~m}^{-2}$. For SZA $<60^{\circ}$ and IWP $>200 \mathrm{~g} \mathrm{~m}^{-2}$, the SFC SW cloud cooling is more than $-300 \mathrm{~W} \mathrm{~m}^{-2}$ (not shown).

The net SFC CRE of ice clouds (Fig. 10b) is mostly positive in the case of high diffuse surface albedo. It asymptotes to about $60-70 \mathrm{~W} \mathrm{~m}^{-2}$ for IWP $>100 \mathrm{~g} \mathrm{~m}^{-2}$. Negative values of net SFC CRE occur under very low SZAs. If diffuse surface albedo is low, a net surface warming by ice clouds can be observed typically for SZA $>80^{\circ}$ and can reach values of up to $79 \mathrm{~W} \mathrm{~m}^{-2}$ (not shown). In principle, the behavior of SW SFC CRE with respect to SZA and IWP is similar to the one shown in Fig. $9 \mathrm{~b}$ for liquid-containing clouds. However, for the same amounts of IWP, the net cooling is much less pronounced. For cases with SZA $<60^{\circ}$ and IWP $>150 \mathrm{~g} \mathrm{~m}^{-2}$, mean net CRE values do not fall below $-290 \mathrm{~W} \mathrm{~m}^{-2}$.

\section{Relative contribution of liquid and ice clouds to surface CRE}

From the previous analyses we can see that liquid and ice in the atmospheric column substantially impact the surface CRE. If a certain amount of liquid, for example, LWP $>5 \mathrm{~g} \mathrm{~m}^{-2}$, is present, it dominates the signal in the SFC CRE. So what is the relative contribution of liquid- and ice-containing clouds to the surface CRE at Ny-Ålesund? Do ice clouds play a significant role at all?

To answer this question we look separately at cases with LWP $>5 \mathrm{~g} \mathrm{~m}^{-2}$ and at cases with IWP $>0 \mathrm{~g} \mathrm{~m}^{-2}$ and LWP $<5 \mathrm{~g} \mathrm{~m}^{-2}$ to roughly separate the signals of mainly liquid-containing and mainly ice-containing clouds. Since ice or liquid may respectively be included in the former or latter case and thus may also contribute to the CRE, a clear separation is not possible. However, from the results of the sensitivity studies, this choice of thresholds seems to be reasonable. Figure 11 shows the monthly mean frequency of occurrence of these two cloud situations. The FOC of cases with LWP $>5 \mathrm{~g} \mathrm{~m}^{-2}$ shows values of up to $80 \%$ in summer and down to $10 \%$ in winter and follows the monthly time series of the 


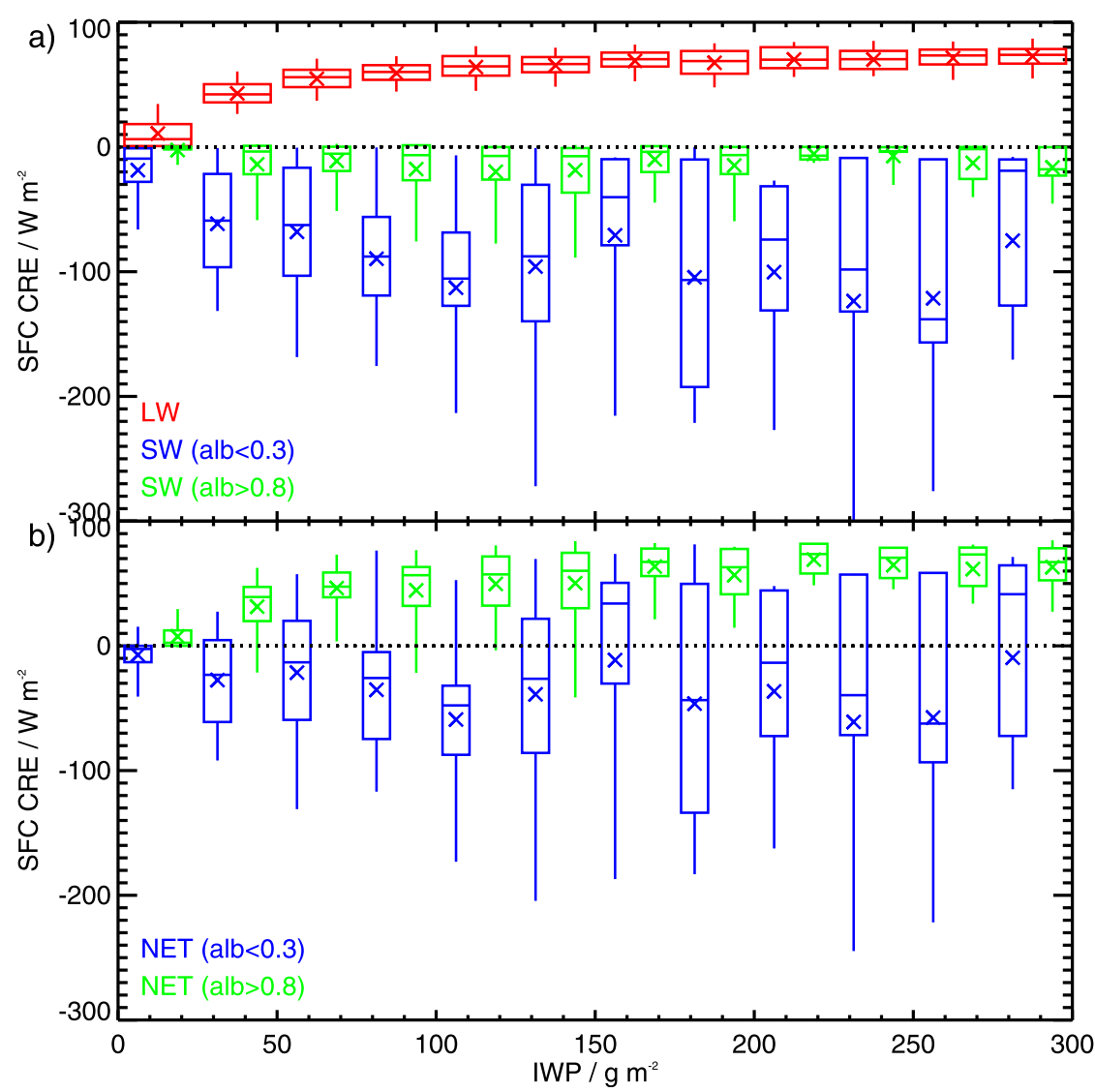

FIG. 10. (a) Longwave (red) and shortwave and (b) net surface CRE as a function of IWP for cases with low $\left(<5 \mathrm{~g} \mathrm{~m}^{-2}\right) \mathrm{LWP}$. The SW and net CRE are calculated for SZA $<90^{\circ}$ and diffuse surface albedo $<0.3$ (blue) and $>0.8$ (green), respectively. The analysis is based on hourly mean values. The box indicates the 25 th and 75 th percentiles, the whiskers show the minimum and maximum, the horizontal line inside the box is the median, and the $\mathrm{x}$ indicates the mean.

FOC of liquid in the atmospheric column (Fig. 5). As expected, the monthly mean FOC of cases with IWP $>$ $0 \mathrm{~g} \mathrm{~m}^{-2}$ and $\mathrm{LWP}<5 \mathrm{~g} \mathrm{~m}^{-2}$ peaks in winter with a maximum of about $80 \%$ in March 2017 and has a minimum in the summer months with values of less than $10 \%$.
The variability of the monthly FOC of the liquid(LWP $>5 \mathrm{~g} \mathrm{~m}^{-2}$ ) and ice-containing (IWP $>0 \mathrm{~g} \mathrm{~m}^{-2}$ and LWP $<5 \mathrm{~g} \mathrm{~m}^{-2}$ ) clouds is well represented in the contribution of these cloud types to the SFC CRE (Fig. 12). In the LW, in most months, liquid-containing clouds

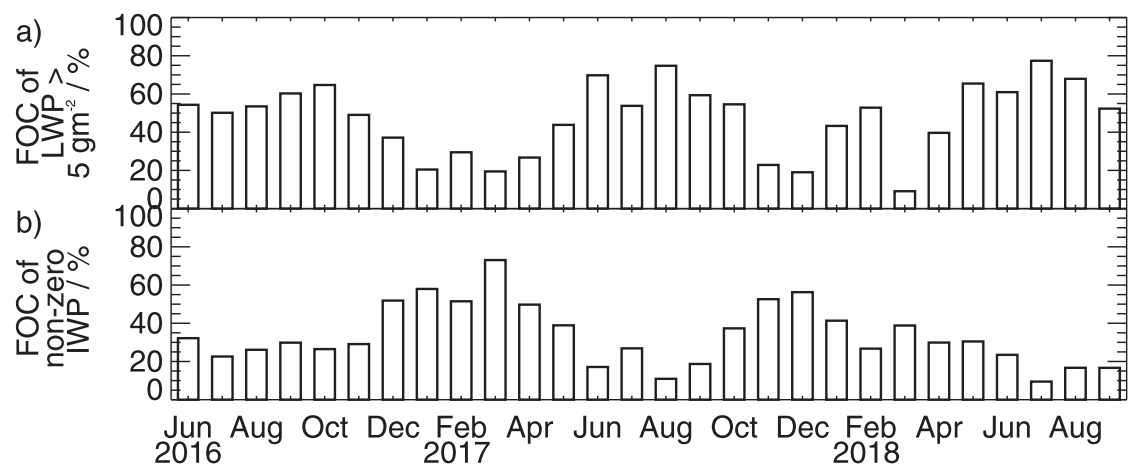

FIG. 11. Monthly mean frequency of occurrence of (a) LWP $>5 \mathrm{~g} \mathrm{~m}^{-2}$ and (b) IWP $>0 \mathrm{~g} \mathrm{~m}^{-2}$ and LWP $<5 \mathrm{~g} \mathrm{~m}^{-2}$. The analysis is based on hourly mean values. 




FIG. 12. (a) LW, (b) SW, and (c) net monthly mean SFC CRE for all conditions (solid line), for cases with LWP $>5 \mathrm{~g} \mathrm{~m}^{-2}$ (dashed line), and for cases with IWP $>0 \mathrm{~g} \mathrm{~m}^{-2}$ and LWP $<5 \mathrm{~g} \mathrm{~m}^{-2}$ (dotted line). The gray solid line in (c) indicates the zero line.

dominate the LW CRE with a relative contribution of $80 \%-95 \%$. Even in winter months, the contribution of liquid to the LW SFC CRE is still high and equals that of ice clouds. Exceptions are January 2017, March 2017 and March 2018. In these months, ice clouds contribute by $60 \%-75 \%$ to the LW SFC CRE.

The SW SFC CRE is most pronounced in summer when SZA and albedo are low. In these months, liquidcontaining clouds clearly dominate the signal and account for $70 \%-98 \%$ of the SW SFC CRE. Thus, during polar day, also the net SFC CRE is basically determined by the radiative effect of liquid-containing clouds. Only during polar night, ice- and liquid-driven radiative effects are equally important with only 2 months, January 2017 and March 2018, in which ice clouds contribute the most to the net SFC CRE.

\section{Summary and outlook}

For the first time, the cloud radiative effect has been characterized for the Arctic site Ny-Ålesund. The cloud radiative effect, that is, the difference between the all-sky and equivalent clear-sky net fluxes, has been derived on the basis of a combination of ground-based remote sensing observations of cloud properties and the application of broadband radiative transfer simulations. More than 2 years of data, that is, from June 2016 to September 2018, have been included in this study.

Uncertainties in the radiative transfer simulations are primarily associated with $3 \mathrm{D}$ effects that are not taken into account by the $1 \mathrm{D}$ radiative transfer calculations, with a misclassification of the scene, with uncertainties in the thermodynamic and aerosol profiles, and with uncertainties in the assumed direct and diffuse albedo as well as with uncertainties in the cloud properties themselves. In particular, for multilayer and mixed-phase clouds, largest uncertainties arise from the uncertainties in the vertical distribution of liquid water. A comparison to observed downward surface radiative fluxes revealed very good agreement in clear-sky situations with LW SW biases of -5 and $13 \mathrm{~W} \mathrm{~m}^{-2}$, respectively. The larger SW bias is most likely related to clouds that were not in the field of view of the cloud radar and ceilometer. Under cloudy conditions, the LW downward surface flux is well reproduced. Here, the mean difference between simulated and observed LW downward fluxes is only $1.6 \mathrm{~W} \mathrm{~m}^{-2}$. Uncertainties in the SW downward flux are larger but of the same order of magnitude as in the study by Shupe et al. (2015). On the basis of the uncertainties of the simulated net surface flux, uncertainties in the average monthly surface CRE are estimated to be smaller than $2 \mathrm{~W} \mathrm{~m}^{-2}$. The actual uncertainties are likely larger because of gaps in the time series of the cloud microphysical properties that occur mainly as a result of missing MWR information. To reduce uncertainties in the retrieved cloud properties, in the future, LWP retrieval could be improved by taking into account observations at higher frequencies, that is, $89 \mathrm{GHz}$, and/or including spectrally resolved infrared measurements that will be available in future. Still, mixed-phase clouds pose a problem, and cloud microphysical retrievals are limited in these cases (Shupe et al. 2008). A detailed analysis of the cloud radar Doppler spectra could provide some additional information here, but no robust methods can be easily applied. 
At Ny-Ålesund, the monthly net surface CRE is positive from September to April/May and negative in the summer months. A similar behavior has been reported for Barrow (Dong et al. 2010). In summer, when surface albedo is low and clouds are efficient in reducing the net SW radiation at the surface, SW surface cooling is larger than the LW warming by clouds. During the rest of the year, LW warming by clouds dominates with an LW SFC CRE of about $50 \mathrm{~W} \mathrm{~m}^{-2}$. The LW SFC CRE at $\mathrm{Ny}$-Ålesund is thus of similar order of magnitude as the one at Barrow (Dong et al. 2010; Cox et al. 2012) and Summit (Miller et al. 2015) but differs from the one at Eureka (27 $\mathrm{W} \mathrm{m}^{-2}$; Cox et al. 2012). The monthly LW SFC CRE follows the seasonal cycle of cloud fraction and of LWP, resulting, for example, in a much smaller LW CRE in November and December 2017 and March 2018 because of a smaller frequency of occurrence of clouds and a lower LWP. When averaging over the year 2017, we find that overall clouds have a warming effect on the surface of about $11.1 \mathrm{~W} \mathrm{~m}^{-2}$ at $\mathrm{Ny}$-Ålesund. The net SFC CRE at Ny-Ålesund is thus slightly larger than the net surface CRE at Barrow $\left(4.5 \mathrm{~W} \mathrm{~m}^{-2}\right.$; Dong et al. 2010) and is much lower than the one at Summit $\left(33 \mathrm{~W} \mathrm{~m}^{-2}\right.$; Miller et al. 2015) because of the lower surface albedo at $\mathrm{Ny}$-Ålesund in the summer months. At the TOA, clouds provide a net cooling of about $-16.1 \mathrm{~W} \mathrm{~m}^{-2}$. The annual average net ATM CRE is $-27.2 \mathrm{~W} \mathrm{~m}^{-2}$. When several complete years of cloud radar observations are available, the year-to-year variability, which has already been indicated by these 28 months of cloud observations, will be analyzed in more detail.

Sensitivity studies showed that the LW SFC CRE can be explained to a large extent by the LWP and saturates at about $75 \mathrm{~W} \mathrm{~m}^{-2}$. Similar results have also been found by Miller et al. (2015), but for a saturation value of $85 \mathrm{~W} \mathrm{~m}^{-2}$ at Summit. The different values are presumably related to the different temperature and humidity conditions at the two sites (Cox et al. 2015). For liquidcontaining clouds, the SFC SW CRE mainly depends on LWP, SZA and surface albedo. At Ny-Ålesund, mainly two albedo states exist representing snow-free and snowcovered surface conditions. In the case of low diffuse surface albedo, SW cooling by liquid-containing clouds is stronger in comparison with cases with high diffuse surface albedo: for low SZAs, the SW cooling higher by up to a factor of 3. For high diffuse albedo values, the net SFC CRE of liquid-containing clouds is positive for SZA $>65^{\circ}$; for low diffuse albedo values, positive net SFC CRE values only occur for SZA $>80^{\circ}$.

Also, ice clouds can have a significant impact on the SFC CRE if LWP is low. When discriminating between "liquid" clouds with LWP $>5 \mathrm{~g} \mathrm{~m}^{-2}$ and "ice" clouds with IWP $>0 \mathrm{~g} \mathrm{~m}^{-2}$ and LWP $<5 \mathrm{~g} \mathrm{~m}^{-2}$, we find that ice clouds can contribute up to $75 \%$ in the net SFC CRE during polar night. Typically, the contributions of liquid and ice clouds to the monthly net SFC CRE are equal in winter, whereas in summer liquid clouds clearly dominate the signal and account for $70 \%-98 \%$ of the net SFC CRE.

Maturilli et al. (2015) showed that Ny-Ålesund experiences a significant positive trend in near-surface air temperature, in particular, in winter. Since we will have warmer winters in the future, the occurrence and amount of liquid might also increase, which will lead to an enhanced surface warming effect by clouds during polar night.

This paper focused on the impact of clouds on the surface radiation fluxes; the next step will be to investigate the vertical redistribution of energy by clouds and how clouds affect the atmospheric heating rates at Ny-Ålesund. Future work will also address similarities and differences to cloud vertical structure and corresponding cloud radiative effects obtained during the 2-month PASCAL cruise in the central Arctic under different sea ice and meteorological conditions. This could also shed light on the principal differences between orographically influenced and free-Arctic meteorological conditions. Furthermore, there are plans to continue the cloud radar measurements at AWIPEV from summer 2019 onward and to expand the time series of vertically resolved cloud observations.

Acknowledgments. We gratefully acknowledge the funding by the Deutsche Forschungsgemeinschaft DFG German Research Foundation) - project number 268020496 - TRR 172, within the Transregional Collaborative Research Center "ArctiC Amplification: Climate Relevant Atmospheric and SurfaCe Processes, and Feedback Mechanisms (AC) ${ }^{3}$." We thank the AWIPEV team for their support in the operation of our instruments at AWIPEV. We appreciate the comments by the three anonymous reviewers.

\section{REFERENCES}

Anderson, T., S. Clough, F. Kneizys, J. Chetwynd, and E. Shettle, 1986: AFGL atmospheric constituent profiles $(0-120 \mathrm{~km})$. Air Force Geophysics Laboratory Tech. Rep. AFGL-TR-86-0110, Hanscom Air Force Base, 46 pp., https://apps.dtic.mil/dtic/tr/ fulltext/u2/a175173.pdf.

Barker, H., and Coauthors, 2003: Assessing 1D atmospheric solar radiative transfer models: Interpretation and handling of unresolved clouds. J. Climate, 16, 2676-2699, https://doi.org/ 10.1175/1520-0442(2003)016<2676:ADASRT>2.0.CO;2.

Cesana, G., J. E. Kay, H. Chepfer, J. M. English, and G. de Boer, 2012: Ubiquitous low-level liquid-containing Arctic clouds: New observations and climate model constraints from CALIPSOGOCCP. Geophys. Res. Lett., 39, L20804, https://doi.org/ 10.1029/2012GL053385.

Clough, S., M. Shephard, E. Mlawer, J. Delamere, M. Iacono, K. CadyPereira, S. Boukabara, and P. Brown, 2005: Atmospheric 
radiative transfer modeling: A summary of the AER codes. J. Quant. Spectrosc. Radiat. Transfer, 91, 233-244, https:// doi.org/10.1016/j.jqsrt.2004.05.058.

Cox, C. J., V. P. Walden, and P. M. Rowe, 2012: A comparison of the atmospheric conditions at Eureka, Canada, and Barrow, Alaska (2006-2008). J. Geophys. Res., 117, D12204, https:// doi.org/10.1029/2011JD017164.

,,--- , and M. D. Shupe, 2015: Humidity trends imply increased sensitivity to clouds in a warming Arctic. Nat. Commun., 6, 10117, https://doi.org/10.1038/ncomms10117.

- , T. Uttal, C. N. Long, M. D. Shupe, R. S. Stone, and S. Starkweather, 2016: The role of springtime Arctic clouds in determining autumn sea ice extent. J. Climate, 29, 6581-6596, https://doi.org/10.1175/JCLI-D-16-0136.1.

Curry, J. A., W. B. Rossow, D. Randall, and J. L. Schramm, 1996: Overview of Arctic cloud and radiation characteristics. J. Climate, 9, 1731-1764, https://doi.org/10.1175/15200442(1996)009<1731:OOACAR > 2.0.CO;2.

de Boer, G., E. W. Eloranta, and M. D. Shupe, 2009: Arctic mixedphase stratus properties from multiple years of surface-based measurements at two high-latitude locations. J. Atmos. Sci., 66, 2874-2887, https://doi.org/10.1175/2009JAS3029.1.

Delanoë, J., and R. J. Hogan, 2010: Combined CloudSat-CALIPSOMODIS retrievals of the properties of ice clouds. J. Geophys. Res., 115, D00H29, https://doi.org/10.1029/2009JD012346.

Dong, X., B. Xi, K. Crosby, C. N. Long, R. S. Stone, and M. D. Shupe, 2010: A 10 year climatology of Arctic cloud fraction and radiative forcing at Barrow, Alaska. J. Geophys. Res., 115, D17212, https://doi.org/10.1029/2009JD013489.

Frisch, A., G. Feingold, C. Fairall, T. Uttal, and J. Snider, 1998: On cloud radar and microwave radiometer measurements of stratus cloud liquid water profiles. J. Geophys. Res., 103, 23 195-23 197, https://doi.org/10.1029/98JD01827.

—, M. Shupe, I. Djalalova, G. Feingold, and M. Poellot, 2002: The retrieval of stratus cloud droplet effective radius with cloud radars. J. Atmos. Oceanic Technol., 19, 835-842, https://doi.org/ 10.1175/1520-0426(2002)019<0835:TROSCD > 2.0.CO;2.

Goosse, H., and Coauthors, 2018: Quantifying climate feedbacks in polar regions. Nat. Commun., 9, 1919, https://doi.org/10.1038/ s41467-018-04173-0.

Hess, M., P. Koepke, and I. Schult, 1998: Optical Properties of Aerosols and Clouds: The software package OPAC. Bull. Amer. Meteor. Soc., 79, 831-844, https://doi.org/10.1175/ 1520-0477(1998)079<0831:OPOAAC $>2.0$. CO;2.

Hogan, R., M. Mittermaier, and A. Illingworth, 2006: The retrieval of ice water content from radar reflectivity factor and temperature and its use in evaluating a mesoscale model. J. Appl. Meteor. Climatol., 45, 301-317, https://doi.org/10.1175/JAM2340.1.

Holben, B. N., and Coauthors, 1998: AERONET-A federated instrument network and data archive for aerosol characterization. Remote Sens. Environ., 66, 1-16, https://doi.org/ 10.1016/S0034-4257(98)00031-5.

Iacono, M. J., J. S. Delamere, E. J. Mlawer, M. W. Shephard, S. A. Clough, and W. D. Collins, 2008: Radiative forcing by longlived greenhouse gases: Calculations with the AER radiative transfer models. J. Geophys. Res., 113, D13103, https://doi.org/ 10.1029/2008JD009944.

Illingworth, A. J., and Coauthors, 2007: CLOUDNET: Continuous evaluation of cloud profiles in seven operational models using ground-based observations. Bull. Amer. Meteor. Soc., 88, 883898, https://doi.org/10.1175/BAMS-88-6-883.

Intrieri, J. M., C. W. Fairall, M. D. Shupe, P. O. G. Persson, E. L Andreas, P. S. Guest, and R. E. Moritz, 2002a: An annual cycle of Arctic surface cloud forcing at SHEBA. J. Geophys. Res., 107, 8039, https://doi.org/10.1029/2000JC000439.

— M. D. Shupe, T. Uttal, and B. J. McCarthy, 2002b: An annual cycle of cloud characteristics observed by radar and lidar at SHEBA. J. Geophys. Res., 107, 8030, https://doi.org/10.1029/ $2000 \mathrm{JC} 000423$.

Jeffries, M. O., J. E. Overland, and D. K. Perovich, 2013: The Arctic shifts to a new normal. Phys. Today, 66, 35-40, https:// doi.org/10.1063/PT.3.2147.

Kanamitsu, M., 1989: Description of the NMC Global Data Assimilation and Forecast System. Wea. Forecasting, 4, 335-342, https://doi.org/10.1175/1520-0434(1989)004<0335:DOTNGD> 2.0.CO;2.

Kay, J. E., and T. L'Ecuyer, 2013: Observational constraints on Arctic Ocean clouds and radiative fluxes during the early 21st century. J. Geophys. Res. Atmos., 118, 7219-7236, https:// doi.org/10.1002/JGRD.50489.

, H. Chepfer, N. Loeb, A. Morrison, and G. Cesana, 2016: Recent advances in Arctic cloud and climate research. Curr. Climate Change Rep., 2, 159-169, https://doi.org/10.1007/ s40641-016-0051-9.

Küchler, N., S. Kneifel, U. Löhnert, P. Kollias, H. Czekala, and T. Rose, 2017: A W-band radar-radiometer system for accurate and continuous monitoring of clouds and precipitation. J. Atmos. Oceanic Technol., 34, 2375-2392, https://doi.org/ 10.1175/JTECH-D-17-0019.1.

Lanconelli, C., M. Busetto, E. G. Dutton, G. König-Langlo, M. Maturilli, R. Sieger, V. Vitale, and T. Yamanouchi, 2011: Polar baseline surface radiation measurements during the International Polar Year 2007-2009. Earth Syst. Sci. Data, 3, 1-8, https://doi.org/10.5194/essd-3-1-2011.

Long, C., and T. Ackerman, 2000: Identification of clear skies from broadband pyranometer measurements and calculation of downwelling shortwave cloud effects. J. Geophys. Res., 105, 15 609-15 626, https://doi.org/10.1029/2000JD900077. , and D. Turner, 2008: A method for continuous estimation of clear-sky downwelling longwave radiative flux developed using ARM surface measurements. J. Geophys. Res., 113, D18206, https://doi.org/10.1029/2008JD009936.

Mace, G. G., S. Benson, and S. Kato, 2006: Cloud radiative forcing at the atmospheric radiation measurement program climate research facility: 2 . Vertical redistribution of radiant energy by clouds. J. Geophys. Res., 111, D11S91, https://doi.org/10.1029/ 2005JD005922.

Maturilli, M., and M. Kayser, 2016: Homogenized radiosonde record at station Ny-Ålesund, Spitsbergen, 1993-2014. PANGAEA, accessed 2 July 2018, https://doi.org/10.1594/ PANGAEA.845373.

, and —, 2017: Arctic warming, moisture increase and circulation changes observed in the Ny-Ålesund homogenized radiosonde record. Theor. Appl. Climatol., 130, 1-17, https:// doi.org/10.1007/s00704-016-1864-0.

— , and K. Ebell, 2018: Twenty-five years of cloud base height measurements by ceilometer in Ny-Ålesund. Earth Syst. Sci. Data, 10, 1451-1456, https://doi.org/10.5194/essd-10-1451-2018.

—_, A. Herber, and G. König-Langlo, 2013: Climatology and time series of surface meteorology in Ny-Ålesund, Svalbard. Earth Syst. Sci. Data, 5, 155-163, https://doi.org/10.5194/ essd-5-155-2013.

,-- , and —-, 2015: Surface radiation climatology for Ny-Ålesund, Svalbard $\left(78.9^{\circ}\right)$, basic observations for trend detection. Theor. Appl. Climatol., 120, 331-339, https://doi.org/ 10.1007/s00704-014-1173-4. 
Miller, N. B., M. D. Shupe, C. J. Cox, V. P. Walden, D. D. Turner, and K. Steffen, 2015: Cloud radiative forcing at Summit, Greenland. J. Climate, 28, 6267-6280, https://doi.org/10.1175/ JCLI-D-15-0076.1.

Mlawer, E., S. Traubman, P. Brown, M. Iacono, and S. Clough, 1997: Radiative transfer for inhomogeneous atmospheres: RRTM, a validated correlated- $k$ model for the longwave. J. Geophys. Res., 102, 16 663-16 682, https://doi.org/10.1029/ 97JD00237.

Nomokonova, T., and K. Ebell, 2019: Cloud microphysical properties retrieved from ground-based remote sensing at Ny-Ålesund (10 June 2016-8 October 2018). University of Cologne, PANGAEA, accessed 11 February 2019, https:// doi.pangaea.de/10.1594/PANGAEA.898556.

,$- \longrightarrow$, U. Löhnert, M. Maturilli, C. Ritter, and E. O'Connor, 2019: Statistics on clouds and their relation to thermodynamic conditions at $\mathrm{Ny}$-Ålesund using ground-based sensor synergy. Atmos. Chem. Phys., 19, 4105-4126, https://doi.org/10.5194/ acp-19-4105-2019.

Rees, W. G., 1993: Infrared emissivities of Arctic land cover types. Int. J. Remote Sens., 14, 1013-1017, https://doi.org/10.1080/ 01431169308904392.

Rossow, W. B., and T.-C. Zhang, 1995: Calculation of surface and top of atmosphere radiative fluxes from physical quantities based on ISCCP data sets: 2. Validation and first results. J. Geophys. Res., 100, 1167-1197, https://doi.org/10.1029/94JD02746.

Screen, J. A., and Coauthors, 2018: Consistency and discrepancy in the atmospheric response to Arctic sea-ice loss across climate models. Nat. Geosci., 11, 155-163, https://doi.org/ 10.1038/s41561-018-0059-y.

Sedlar, J., and M. Tjernström, 2017: Clouds, warm air, and a climate cooling signal over the summer Arctic. Geophys. Res. Lett., 44, 1095-1103, https://doi.org/10.1002/2016GL071959.

—_, and Coauthors, 2011: A transitioning Arctic surface energy budget: The impacts of solar zenith angle, surface albedo and cloud radiative forcing. Climate Dyn., 37, 1643-1660, https:// doi.org/10.1007/s00382-010-0937-5.

Serreze, M. C., and R. G. Barry, 2011: Processes and impacts of Arctic amplification: A research synthesis. Global Planet. Change, 77, 85-96, https://doi.org/10.1016/j.gloplacha.2011.03.004.

Shupe, M. D., and J. M. Intrieri, 2004: Cloud radiative forcing of the Arctic surface: The influence of cloud properties, surface albedo, and solar zenith angle. J. Climate, 17, 616-628, https://doi.org/ 10.1175/1520-0442(2004)017<0616:CRFOTA > 2.0.CO;2.

_- P. Kollias, S. Y. Matrosov, and T. L. Schneider, 2004: Deriving mixed-phase cloud properties from Doppler radar spectra. J. Atmos. Oceanic Technol., 21, 660-670, https://doi.org/10.1175/1520-0426(2004)021<0660:DMCPFD> 2.0.CO;2.

—_, and Coauthors, 2008: A focus on mixed-phase clouds: The status of ground-based observational methods. Bull. Amer. Meteor. Soc., 89, 1549-1562, https://doi.org/10.1175/ 2008BAMS2378.1.

_ , and Coauthors, 2013: High and dry: New observations of tropospheric and cloud properties above the Greenland Ice Sheet. Bull. Amer. Meteor. Soc., 94, 169-186, https://doi.org/ 10.1175/BAMS-D-11-00249.1.

—, D. D. Turner, A. Zwink, M. M. Thieman, E. J. Mlawer, and T. Shippert, 2015: Deriving Arctic cloud microphysics at Barrow, Alaska: Algorithms, results, and radiative closure. J. Appl. Meteor. Climatol., 54, 1675-1689, https://doi.org/ 10.1175/JAMC-D-15-0054.1.

Stroeve, J. C., M. C. Serreze, M. M. Holland, J. E. Kay, J. Maslanik, and A. P. Barrett, 2012: The Arctic's rapidly shrinking sea ice cover: A research synthesis. Climatic Change, 110, 1005-1027, https://doi.org/10.1007/s10584-011-0101-1.

Turner, D., 2007: Improved ground-based liquid water path retrievals using a combined infrared and microwave approach. J. Geophys. Res., 112, D15204, https://doi.org/10.1029/ 2007JD008530.

Verlinde, J., B. D. Zak, M. D. Shupe, M. D. Ivey, and K. Stamnes, 2016: The ARM North Slope of Alaska (NSA) sites. The Atmospheric Radiation Measurement (ARM) Program: The First 20 Years, Meteor. Monogr., No. 57, Amer. Meteor. Soc., https://doi.org/10.1175/AMSMONOGRAPHS-D-15-0023.1.

Wang, X., and J. Key, 2005: Arctic surface, cloud, and radiation properties based on the AVHRR Polar Pathfinder dataset. Part I: Spatial and temporal characteristics. J. Climate, 18, 2558-2574, https://doi.org/10.1175/JCLI3438.1.

Wendisch, M., and Coauthors, 2017: Understanding causes and effects of rapid warming in the Arctic. Eos, Trans. Amer. Geophys. Union, 98,22-26, https://doi.org/10.1029/2017EO064803.

_- , and Coauthors, 2019: The Arctic cloud puzzle: Using ACLOUD/PASCAL multi-platform observations to unravel the role of clouds and aerosol particles in Arctic amplification. Bull. Amer. Meteor. Soc., 100, 841-871, https://doi.org/10.1175/ BAMS-D-18-0072.1.

Yang, F., K. Mitchell, Y.-T. Hou, Y. Dai, X. Zeng, Z. Wang, and X.-Z. Liang, 2008: Dependence of land surface albedo on solar zenith angle: Observations and model parameterization. J. Appl. Meteor. Climatol., 47, 2963-2982, https://doi.org/ 10.1175/2008JAMC1843.1. 